DEPARTMENT OF ENVIRONMENT, TECHNOLOGY AND TECHNOLOGY MANAGEMENT

\title{
Efficient metaheuristics to solve the intermodal terminal location problem
}

Kenneth Sörensen, Christine Vanovermeire \& Sylvie Busschaert

\author{
UNIVERSITY OF ANTWERP \\ Faculty of Applied Economics \\ Stadscampus \\ Prinsstraat 13, B.226 \\ BE-2000 Antwerpen \\ Tel. +32(0)32654032 \\ Fax +32(0)3 2654799 \\ http://www.ua.ac.be/tew
}




\title{
FACULTY OF APPLIED ECONOMICS
}

\author{
DEPARTMENT OF ENVIRONMENT, \\ TECHNOLOGY AND TECHNOLOGY MANAGEMENT \\ Efficient metaheuristics to solve the intermodal \\ terminal location problem
}

Kenneth Sörensen, Christine Vanovermeire \& Sylvie Busschaert

RESEARCH PAPER 2012-001

JANUARY 2012

University of Antwerp, City Campus, Prinsstraat 13, B-2000 Antwerp, Belgium Research Administration - room B.226

phone: (32) 32654032

fax: (32) 32654799

e-mail: joeri.nys@ua.ac.be

The papers can be also found at our website:

www.ua.ac.be/tew (research $>$ working papers) \&

www.repec.org/ (Research papers in economics - REPEC)

$D / 2012 / 1169 / 001$ 


\title{
Efficient metaheuristics to solve the intermodal terminal location problem
}

\author{
Kenneth Sörensen* Christine Vanovermeire \\ Sylvie Busschaert \\ University of Antwerp Operations Research Group ANT/OR
}

February 2011

\begin{abstract}
Determining the optimal number and location of intermodal transshipment terminals is a decision that strongly influences the viability of the intermodal transportation alternative. In this paper, we develop a model and an optimization method that provides policy makers with a tool to help them take these decisions.

The objective of the terminal location problem described in this paper is to determine which of a set of potential terminal locations to use and which not and how to route the supply and demand of a set of customers (representing zones of supply and demand) through the network (by both uni- and intermodal transport) so as to minimize the total cost. We develop two different metaheuristic procedures that both consist of two phases: a solution construction phase and a solution improvement phase. The first metaheuristic constructs solutions using a GRASP procedure, the second one uses the relatively unknown attribute based hill climber (ABHC) heuristic. Innovative in our approach is the integration of a fast heuristic procedure to approximate the total cost given the set of open terminals.

Both metaheuristics are compared to the results of an MIP solver. A thorough performance assessment uncovers that both metaheuristics generate close-to-optimal solutions in very short computing times. An argument in favor of the ABHC approach is that it is parameter-free and hence more transparent and likely to be accepted in a business or policy environment.
\end{abstract}

Key words: Intermodal transportation, terminal location, metaheuristics

\footnotetext{
*Corresponding author: Kenneth Sörensen, University of Antwerp, Prinsstraat 13, 2000 Antwerp, Belgium, kenneth.sorensen@ua.ac.be, tel: +32 326540 40, fax: +32 32654901
} 


\section{Introduction}

After the establishment of the Kyoto protocol in 1997, Europe dedicated itself to a significant reduction in the emission of greenhouse gases. The aim was to reduce the general amount of greenhouse gases in the atmosphere by 8\% compared to 1990 in the period 2008-2012. Although the EU27 had already achieved a general reduction of $7.3 \%$ by 2006 , the reduction in $\mathrm{CO}_{2}$-emissions was a lot less promising. This lack of a significant decrease in $\mathrm{CO}_{2}$ can be attributed almost entirely to the transportation sector which accounts for $30 \%$ of all $\mathrm{CO}_{2}$-emissions. Moreover, road transportation is by far the most polluting transport mode,

so responsible for $71 \%$ of all transport $\mathrm{CO}_{2}$-emissions (UIRR, 2009). These numbers clearly show the need to reduce the environmental impact of transportation activities in general, and to reduce $\mathrm{CO}_{2}$-emissions stemming from road transportation in particular.

Multimodal transportation is one of the most promising approaches to achieve these goals (Bühler and Jochem, 2008). It is defined as the transportation of goods by at least two different modes of transport (UNECE, 2009). In this paper we focus on a particular type of multimodal transportation called intermodal transportation. This term is used for the multimodal transport of goods in one and the same intermodal transport unit by successive modes of transport, without handling of the goods themselves when changing modes. An excellent example of an intermodal transportation network is the worldwide transportation network of containers. Because containers are highly standardized, they can be shipped from and to virtually any place in the world through an enormous network of transshipment terminals (ports, railway stations) and by many different transport modes (ships, barges, trains, trucks).

Since different transport modes have different environmental profiles, i.e., their burden on the environment per tonne-kilometer differs significantly, combining transport modes offers new opportunities for reducing the carbon footprint of the transportation sector. Nevertheless, intermodal transportation is still a long way from becoming an economically viable alternative for road transportation (Janic, 2007). In industry, modal choices are mainly based on economical criteria such as cost, flexibility and service level. For small to medium distances, no other transport mode (or combination of transport modes) can currently compete with road transportation on these criteria.

The low level of maturity of intermodal transportation in Europe can be explained to large extent by the poor intermodal infrastructure and connectivity of transport modes. Since the initial drayage move and terminal operations contribute in a significant way to transit time and costs of intermodal transportation services, the location of the intermodal terminals plays an important role in enhancing the attractiveness of intermodal transportation 
(Pedersen, 2005). An intermodal freight terminal is defined as a location equipped for transshipment of intermodal transport units (ITUs) between modes (UNECE, 2009). The policy decision where to locate new terminals are complicated ones, often involving many stakeholders (e.g., terminal operators, freight operators, local communities, investors and policy makers) with their own objecives (Sirikijpanichkul and Ferreira, 2005) and supporting these decisions by adequate quantitative methods requires considerable simplification of reality.

In this paper we use the model of Arnold et al. (2001), in which the intermodal terminal location problem is formulated as a mixed-integer programming problem. In their model, a set of potential terminal locations is given, each with a given capacity and a fixed cost that is incurred when the terminal is opened. Additionally, a set of customers is given, representing origins and destinations of demand that is to be transported through the network from its origin to its destination. For each demand (i.e., each pair of an origin customer and a destination customer), the unimodal transportation cost is given, as well as the cost of routing this demand via any pair of terminals. In this model two decisions need to be taken simultaneously. The first decision is which of the set of potential terminals to open and which not. The second is how to route each of the individual demands through the network. This can be done in a unimodal way, i.e., directly from the origin to the destination customer, or in an intermodal way, by transporting it from the origin customer to a terminal, then to a terminal closer to the destination customer and finally to the destination customer itself. The objective of the model developed by Arnold et al. (2001) is to minimize the total cost, which is the sum of fixed costs for opening terminals and the cost of routing all demands through the network. A more detailed and formal description of this problem is given in Section 3.

80 The model used in this paper and the methods we have developed to solve it, can be used to support high-level decision making on the layout of an intermodal terminal transportation network. This decision occurs both in a policy-making context and a business context. For example, if the Belgian government wants to determine which of a set of potential railway stations for container transport it should build, our methods could be used to quickly find a good solution under several different scenarios. Similarly, if a large trading company wants to determine which existing ports it should use to ship its containers from its production plants to its customers, it could similarly employ our methods. However, notwithstanding the fact that the decision where to locate intermodal transshipment terminals is a longterm decision for which, in principle, significant calculation time is availabe, the heuristics developed in this paper are able to compute near-optimal solutions in very short computing times. The reason for this design choice is that the model used in this paper - as well as other mathematical models of similar problems - is only able to capture part of the complex societal and economical reality of the real decision situation. As a result, such complex 
decisions are usually not taken in a one-shot way, but are the result of careful analysis in which several scenarios are evaluated. For example, a courier company that is planning to use a certain airport as a hub will be interested in the consequences on its operations of a government restriction on night time flights. A mathematical model and optimization method can therefore only aid a decision maker by providing him with insight into the optimal locations of terminals under varying circumstances. The best way to support such decisions is by integrating the method in an interactive decision tool, where the decision maker can manually adjust the parameters of the model and quickly re-optimize. The underlying method of such a what-if analysis tool should be able to respond quickly to such parameter adjustment.

Arnold et al. (2001) propose to solve their model using a branch-and-bound procedure. However, since this terminal location problem is NP-hard (see Appendix A), such exact algorithms can only be used for small instances. In order to solve real-life instances of the intermodal terminal location problem, it is therefore necessary to use faster, heuristic solution methods. The objective of this paper is to provide decision makers with a new, fast but effective method to solve the terminal location problem as described by Arnold et al. (2001). More specifically, we develop two different heuristics, based on respectively the attribute based hill climber (ABHC) and the GRASP metaheuristic frameworks. Both heuristics are compared to each other in terms of solution quality, speed and ease of use.

The remainder of this paper is organized as follows. In Section 2 we survey the literature on the intermodal terminal location problem and discuss the similarities and differences with related optimization problems. Section 3 presents the mathematical model of the terminal location problem, for which we develop two heuristic solution approaches in Section 4 . These approaches are tested in Section 5. Section 6 concludes and provides pointers for future research.

\section{Literature}

Although research on intermodal transportation is still in a rather immature phase (Bontekoning et al., 2004), the strategic importance of intermodal transshipment terminals within intermodal networks is demonstrated by the amount of literature that has been accorded to this subject in recent years. A wide variety of topics related to intermodal terminals has been discussed, ranging from the main characteristics and the different types of intermodal terminals (e.g., Sirikijpanichkul and Ferreira, 2005) over measuring terminal performance (e.g., Ferreira and Sigut, 1993) to an analysis of the terminal market and a description of its most important stakeholders (e.g., Wiegmans et al., 1998). 
Both the complexity and importance of optimally locating intermodal terminals within the transport network has been acknowledged early on by many authors stemming from different research fields. Macharis and Bontekoning (2004) provide an overview of the most prominent research efforts within the field of operations research. They distinguish three different approaches to determine the optimal location of transshipment terminals. Although some authors propose the use of simulation techniques (e.g., Meinert et al., 1998) and multicriteria analysis (e.g., Macharis and Verbeke, 1999) to select the most appropriate location from a pool of potential sites, the dominant approach is the application of network models (e.g., Rutten, 1995; Groothedde and Tavasszy, 1999).

Several commonly investigated optimization problems are closely related to the intermodal terminal location problem. The capacitated (fixed charge) facility location problem (CFCLP), for which metaheuristics are frequently used as a solution method, shows some similarities. The CFCLP considers the problem of selecting a subset of facilities from an existing set of potential locations that have to supply a set of customers at a minimum cost. Each customer has an associated demand to be met and each facility has a finite amount of supply available (Venables and Moscardini, 2008). There are quite a number of differences however, with the intermodal terminal location problem. Most importantly, since demand in the CFdoes not have a destination, but only an origin, demand cannot be transported between facilities. Different metaheuristics have been applied successfully to the CFCLP, such as simulated annealing (e.g., Bornstein and Azlan, 1998), genetic algorithms (e.g., Jaramillo et al., 2002), tabu search (e.g., Filho and Galvão, 1998) and ant colony optimization (e.g., Venables and Moscardini, 2006).

The multicommodity capacitated (fixed charge) network design problem (MCNDP) (Crainic et al., 2001; Frangioni and Gendron, 2009), in which a set of demands have to be routed through a network, shows some similarities to the intermodal terminal location problem, but differs in that capacities are defined on arcs and not on nodes and that fixed costs have to be paid if an arc is used (instead of a node). This leads to quite different models and algorithms.

The intermodal terminal location problem discussed in this paper can be seen as a hub location problem. We refer to Alumur and Kara (2008) for a recent survey of hub location problems and algorithms to solve them. Many different hub location problems have been defined, but the multiple-allocation capacitated hub location problem with fixed costs comes closest to the problem discussed in this paper. The main difference is in the way demand is routed through the network: hub location problems do not allow transportation between customers directly (which we call unimodal transportation in this paper), but do allow transport via only one hub, which does not make much sense in the case of inter- 
modal transportation. The first LP formulation for the multiple allocation capacitated hub location problem (without fixed costs) is due to Campbell (1994), but papers on capacitated hub location problems have been few and far between. An efficient algorithm for a capacitated hub location problem can be found in Ebery et al. (2000). Boland et al. (2004) develop preprocessing procedures and tightening constraints. A different formulation and an algorithm can be found in Marín (2005), who also confirm the scarceness of papers on this topic.

Intermodal terminal location is a complicated decision with many stakeholders. Some authors attempt to capture the complex reality by presenting extensions of existing optimization models that include, e.g., non-linear cost functions (Racunica and Wynter, 2005). Others have used agent-based techniques in which different stakeholders are represented by different agents (see Sirikijpanichkul et al., 2007, for an overview).

As mentioned, in this paper we take the position that locating intermodal terminals is such a complicated decision that no model - however complex - is going to capture more than a fraction of the real problem. Any model that is going to be used in practice should therefore be simple and understandable and any method to solve it should be able to quickly locate a reasonable solution, so that the method can be embedded in a decision support system. For these reasons, we use the intermodal terminal location model presented by Arnold et al. (2001). To the best of our knowledge, this paper presents the first metaheuristic for this problem.

\section{Model Formulation}

In Arnold et al. (2001), the authors propose a model to determine the optimal rail/road network in Belgium by means of integer linear programming. The optimal network is defined as the network configuration that minimizes the total cost, i.e. the sum of uni- and intermodal transportation costs and fixed terminal location costs.

The model described in Arnold et al. (2001), which is also used in this paper, can be described as follows. Let $I$ be the set of all origins/destinations and $K$ the set of all potential terminal locations in the network. Each origin/destination-pair $(i, j)$ has associated with it a positive and fixed amount $q_{i j}$ of goods that should be transported (which we call the demand, with $q_{i i}=0$ ), a decision variable $w_{i j}$ and a set of decision variables $x_{i j}^{k m}$. The variable $w_{i j}$ represents the fraction of the demand $q_{i j}$ transported unimodally whereas the set of variables $x_{i j}^{k m}$ relate to the fraction of the demand $q_{i j}$ shipped intermodally using terminals $k, m \in K . c_{i j}^{k m}$ is the unit cost of transporting demand between $i$ and $j$ through terminals $k$ and $m$ and $c_{i j}$ is the unit cost of transporting demand directly from $i$ to $j$ 
without any intermediate intermodal operations. In turn, each potential terminal location $k \in K$ has associated with it a positive and fixed capacity $C_{k}$, a fixed $\operatorname{cost} F_{k}$ and a decision variable $y_{k}$ which is equal to 1 when terminal $k$ is open and equal to 0 otherwise.

$$
\begin{array}{lr}
\min \sum_{i, j \in I} \sum_{k, m \in K} c_{i j}^{k m} x_{i j}^{k m}+\sum_{i, j \in I} c_{i j} w_{i j}+\sum_{k \in K} F_{k} y_{k} & \\
\text { s.t. } & \forall k, m \in K, \forall i, j \in I \\
\quad x_{i j}^{k m} \leqslant q_{i j} y_{k} & \forall k, m \in K, \forall i, j \in I \\
x_{i j}^{k m} \leqslant q_{i j} y_{m} & \forall i, j \in I \\
\sum_{k, m \in K} x_{i j}^{k m}+w_{i j}=q_{i j} & \forall k \in K \\
\sum_{i, j \in I} \sum_{m \in K} x_{i j}^{k m}+\sum_{i, j \in I} \sum_{m \in K} x_{i j}^{m k} \leqslant C_{k} & \forall i, j \in I, \forall k, m \in K \\
w_{i j} \geqslant 0, x_{i j}^{k m} \geqslant 0, x_{i j}^{k k}=0 & \forall k \in K \\
y_{k} \in\{0,1\} & \forall k
\end{array}
$$

The objective function (1) minimizes the total transportation cost associated with all transportation flows within the network. It is composed of three parts. The first part represents the cost of all transportation flows that require a change in transportation mode whereas the second part refers to the unimodal transportation flows. The third part equals the total fixed cost associated with all opened terminals in the network. Constraints (2) and (3) ensure that no goods can be transported using a certain terminal, unless this terminal is open. Constraints (4) stipulate that, for each origin/destination-pair, the sum of all goods transported unimodally and intermodally should equal the demand associated with this origin/destination-pair. Constraints (5) bring into account the limited capacity of the intermodal terminals. Constraints (6) ensure that only positive amounts are transported and that no demand is transported using only one terminal. Finally, constraints (7) enforce that a terminal is either used or not.

The model can be used for policy-making purposes, in which both origins and destinations should be interpreted as zones of economic activity that ship goods through the network to each other. Each zone can be both a supply and a demand point at the same time.

A graphical representation for a simple problem with 3 customers, 3 origin-destination flows, and 3 terminals is shown in Figure 1. All terminals are assumed to have a capacity of 100 units (indicated between brackets). The left part of the figure shows the (unimodal) transport streams if no terminals are open. The right part visualizes how these streams are 
rerouted when terminals $t_{1}$ and $t_{2}$ are open and $t_{3}$ is closed. The flow from $c_{1}$ to $c_{2}$ is still shipped by unimodal transport, whereas the flow between $c_{1}$ and $c_{3}$ is shipped entirely by intermodal transport. The flow between $c_{2}$ and $c_{3}$ is shipped only partially by intermodal transport, due to the limited capacity of the terminals.

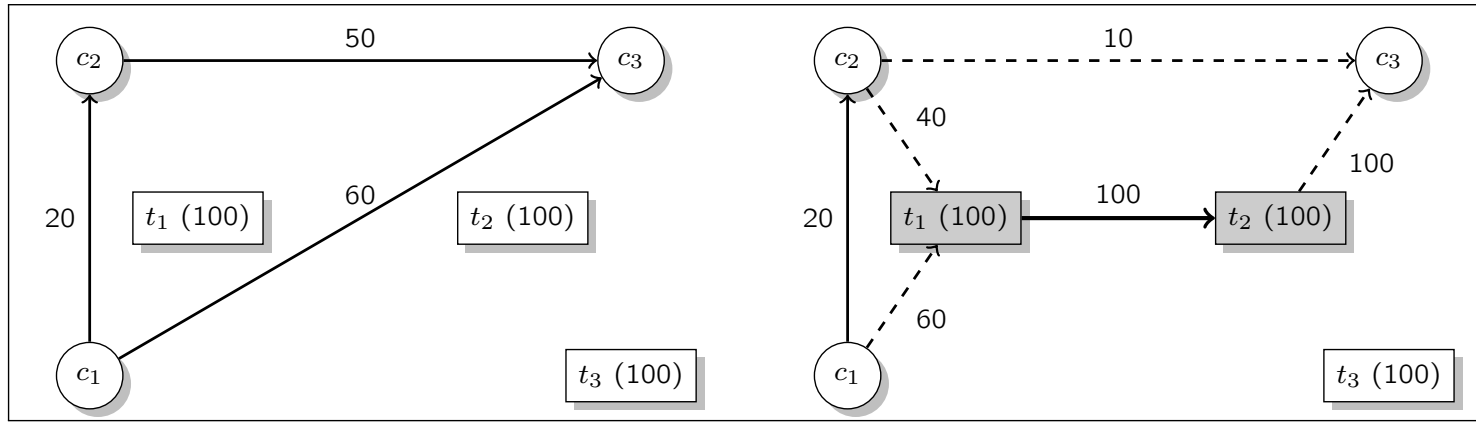

Figure 1: Example of the intermodal terminal location problem

In Appendix A we provide a mathematical proof that this problem is NP hard.

\section{Efficient metaheuristics for the intermodal terminal location problem}

In this section, we propose two different metaheuristics to solve the intermodal terminal location problem described in the previous section. Both heuristics consist of two phases: a construction phase (see Section 4.2) and an improvement phase (see Section 4.3). In the construction phase, initial solutions are built by a constructive metaheuristic and stored in an archive. The improvement phase - as the name suggests - improves the solutions in the archive. In both phases, the heuristics make use of a heuristic evaluation procedure to quickly evaluate solutions (see Section 4.1). The two metaheuristics differ in the way initial solutions are constructed and in the way the archive is maintained. The first metaheuristic uses a GRASP (greedy randomized adaptive search procedure) construction procedure, the second one an ABHC (attribute based hill climber). The local search heuristics used in the improvement phase are identical for both metaheuristics. Figure 2 shows the high-level structure of the metaheuristics.

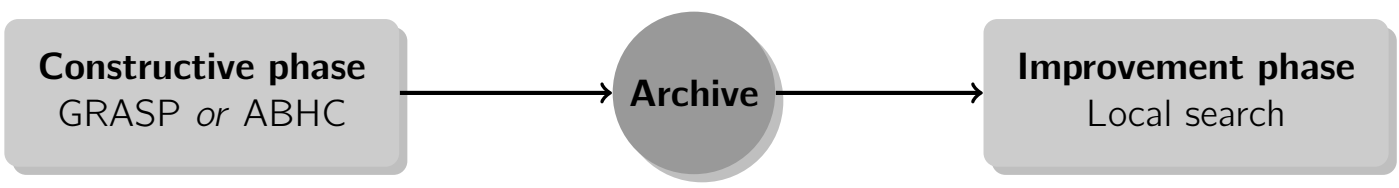

Figure 2: Structure of the metaheuristics 
It is important to note that solutions in the archive should not only be of high quality, they should also be diverse to ensure that they are not all in the same basin of attraction (i.e., the improvement heuristics should not end up in the same local optimum when improving the solutions in the archive). The mechanisms for ensuring diversity differ depending on the constructive metaheuristic (GRASP or ABHC) used.

\subsection{Problem decomposition and heuristic evaluation procedure}

In our approach, the terminal location problem is decomposed in a master and a subproblem. A solution of the master problem corresponds to a status open or closed for each potential terminal location, whereas the subproblem determines the way each demand is routed through the network, given the open terminals. Given a solution to the master problem, i.e., a set $\bar{K} \subseteq K$ of open terminals, the subproblem is the following LP.

$$
\begin{aligned}
& \min \sum_{i, j \in I} \sum_{k, m \in \bar{K}} c_{i j}^{k m} x_{i j}^{k m}+\sum_{i, j \in I} c_{i j} w_{i j}+F_{\bar{K}} \\
& \text { s.t. } \\
& \sum_{k, m \in \bar{K}} x_{i j}^{k m}+w_{i j}=q_{i j} \quad \forall i, j \in I \\
& \sum_{i, j \in I} \sum_{m \in \bar{K}} x_{i j}^{k m}+\sum_{i, j \in I} \sum_{m \in \bar{K}} x_{i j}^{m k} \leqslant C_{k} \quad \forall k \in \bar{K} \\
& w_{i j}, x_{i j}^{k m} \geqslant 0, x_{i j}^{k k}=0 \quad \forall i, j \in I, \forall k, m \in \bar{K}
\end{aligned}
$$

550 The objective function value of an optimal solution of the subproblem in Eqs. (8-11) is equal to the total cost of the corresponding solution to the original problem. Unfortunately, for large instances, the number of decision variables and constraints in this LP becomes very large and it quickly becomes impractical or even impossible to solve the problem to optimality. Given the fact that the heuristics need to evaluate many solutions, both in the construction and the improvement phase, we develop a fast heuristic evaluation procedure to quickly calculate a heuristic objective function value. This value is an approximation of the exact objective function value of a master problem solution (i.e., the objective function value of the optimal solution of the subproblem LP).

The heuristic evaluation procedure works as follows. For each pair of customers, one needs to decide how the corresponding demand will be shipped, i.e., unimodally, intermodally, or using a combination of both. In order to minimize the total cost and taking into account 
the terminal capacity constraints, it is important to allocate the capacity of each terminal to those shipments that benefit the most from using it.

In order to achieve this, the heuristic evaluation procedure creates for each demand $q_{i j}$, i.e., for each pair of customers $(i, j)$ a list $P_{i j}$ of routes $M_{i j}^{k m}$ (connecting customers $i$ to $j$ through terminals $k$ and $m$ ) for which the cost $c_{i j}^{k m}$ of shipping the associated demand via this trajectory is smaller than the unimodal cost $c_{i j}$. All lists $P_{i j}$ are sorted in order of increasing cost, and the unimodal route with $\operatorname{cost} c_{i j}$ is added in final position. All lists $P_{i j}$ therefore contain all paths to transport demand $q_{i j}$ through the network, in order of increasing cost. If the cheapest trajectory means moving the demand unimodally (i.e., $\left.c_{i j} \leqslant c_{i j}^{k m} \forall k, m\right)$, then $P_{i j}$ contains only one path. If this is not the case, we calculate the difference in cost between the best and the second best trajectory. This value is called the regret $\left(r_{i j}\right)$ and is further used to determine the sequence in which demands should be assigned to terminals. Since demands with a large regret imply a significant increase in total cost if not assigned to their cheapest trajectory, they should therefore be assigned with large priority. A so-called regret list $R$ is created that contains all demands $q_{i j}$, sorted in decreasing order of regret. Starting with the first demand on the regret list and continuing down the list, each demand is then assigned in the best possible way (determined by its list $\left.P_{i j}\right)$ that is still available. If, for any origin/destination-pair, there is not enough terminal capacity available to assign all demand to its cheapest trajectory, the surplus demand is assigned to the second cheapest trajectory and so on until the unimodal route becomes the most profitable. A pseudo-code version of the heuristic evaluation procedure can be found in Algorithm 1.

The calculations of the lists $P_{i j}$ and $R$ are performed before the actual optimization process order not to slow down the optimization process later on. To calculate the regrets, since at this point we do not yet know which terminals will be open and which will be closed, we assume a configuration in which all terminals are open.

\subsection{Construction phase: GRASP or ABHC}

\subsubsection{GRASP}

GRASP, or greedy randomized adaptive search procedure, is a multi-start metaheuristic the objective of which is to build a feasible solution by starting from an empty solution and adding one element at a time. Typical of the GRASP metaheuristic is that it balances greedyness (selecting the best element at each iteration) and randomness (selecting a random element at each iteration) and is able to combine the advantages of both approaches. Our GRASP heuristic for the terminal location problem starts from a solution in which all 


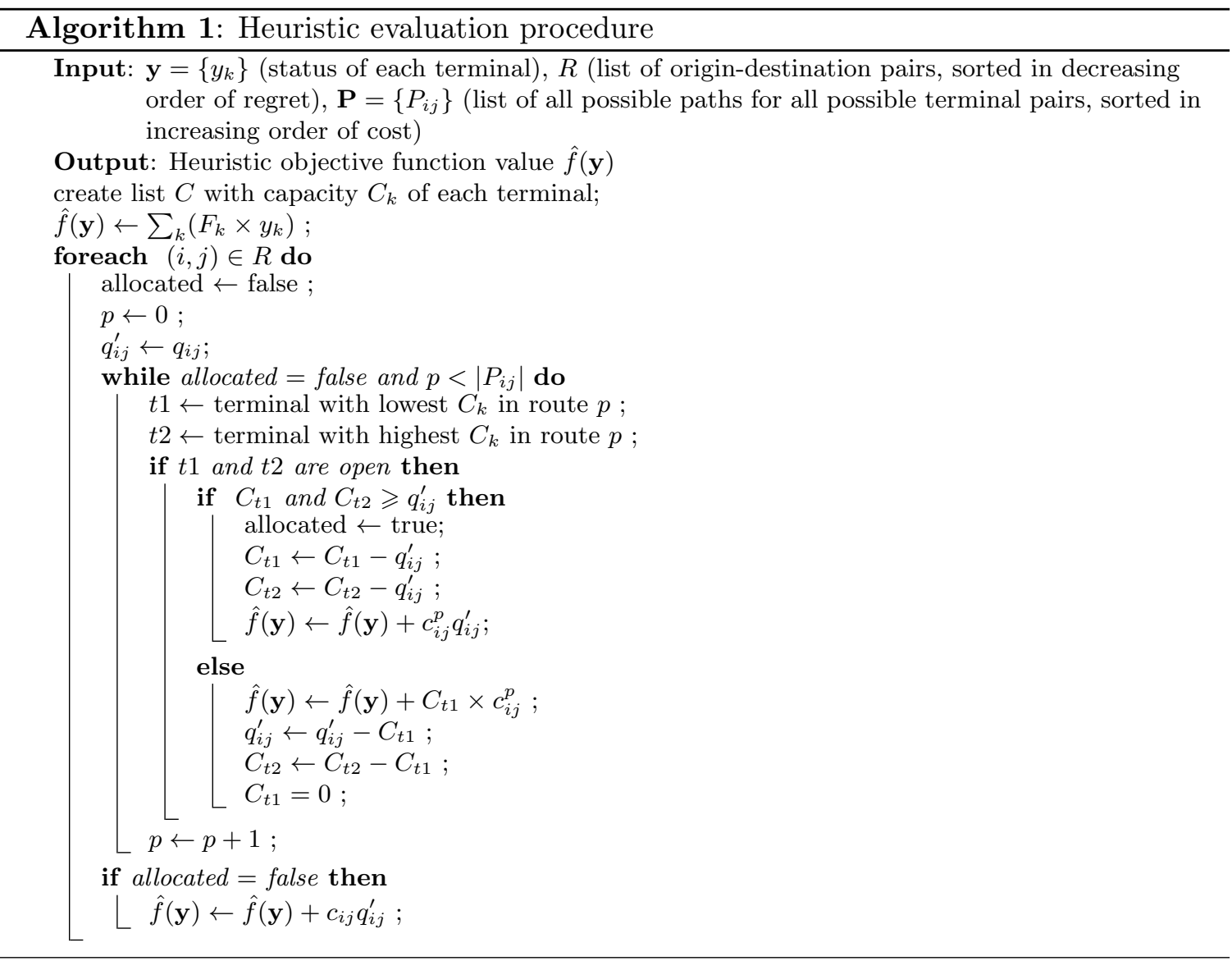


terminals are closed and opens one terminal at a time. A pseudo-code description of the GRASP algorithm is given in Algorithm 2.

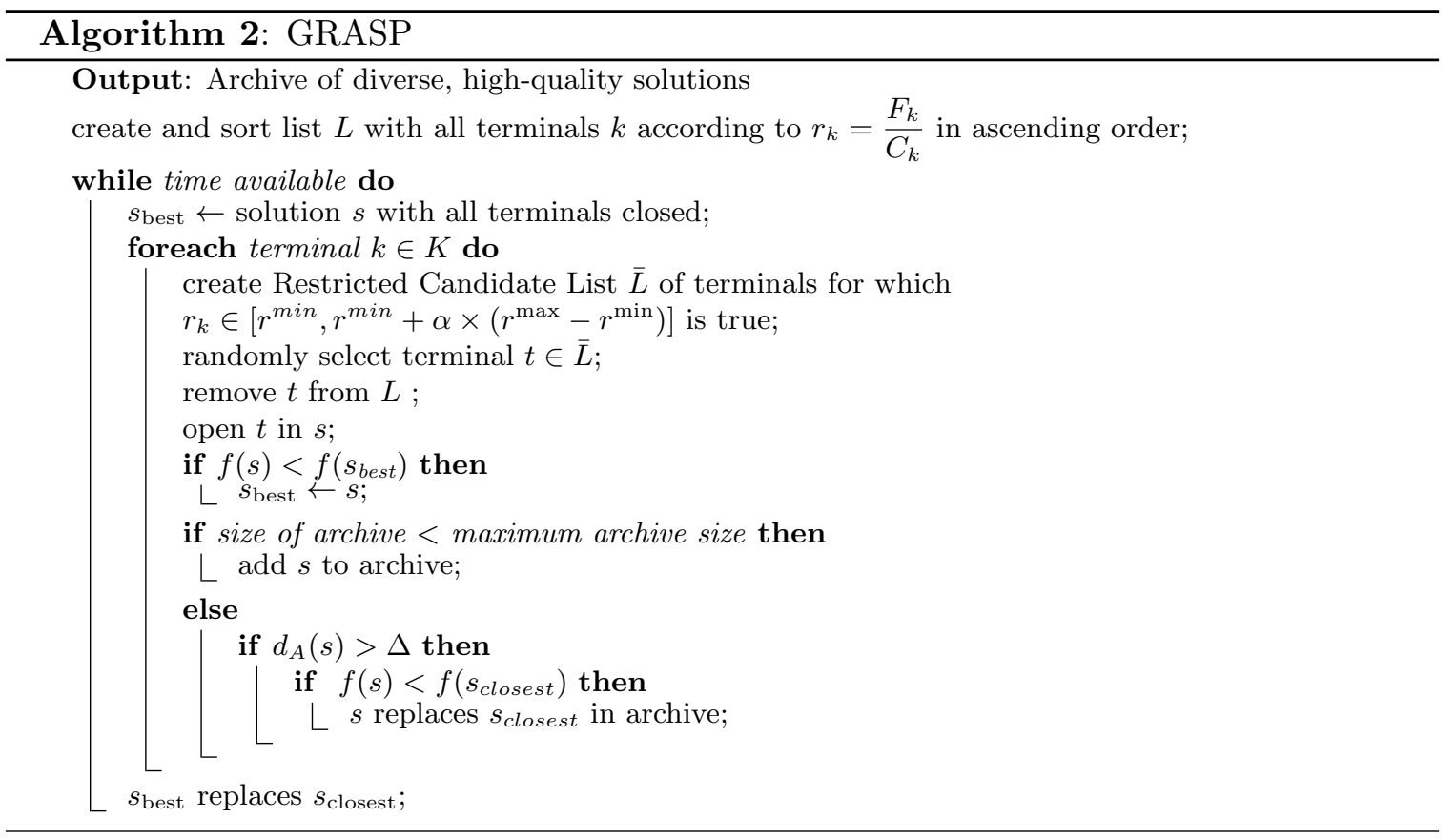

The order in which the terminals are opened, is determined on the basis of the fixed cost/capacity-ratio of each terminal. For each terminal $k \in K$, this ratio is calculated as $r_{k}=F_{k} / C_{k}$. At each iteration, the GRASP algorithm determines a restricted candidate list (RCL) that consists of the best terminals, i.e., those terminals that have the lowest fixed cost/capacity-ratio. In our procedure, the restricted candidate list is composed of all terminals that satisfy the following constraint: $r_{k} \in\left[r^{\min }, r^{\min }+\alpha\left(r^{\max }-r^{\min }\right)\right]$, with threshold parameter $\alpha \in[0,1]$. The terminal to be added is then randomly selected from the restricted candidate list and the objective value of the newly constructed solution is calculated using the heuristic evaluation procedure described earlier in this paper. Then, the restricted candidate list is updated to make sure that the element under consideration is no longer available for selection and the above process is repeated.

To preserve the diversity of the archive, a solution is only accepted into the archive if it fulfils two criteria. First, the constructed solution should differ sufficiently from all solutions currently in the archive. To determine the degree of difference between two solutions, the Hamming distance $d$ is used, i.e., the number of terminals that is not in the same state (open or closed) in both solutions.

$$
d\left(\mathrm{~s}_{1}, \mathrm{~s}_{2}\right)=\sum_{k \in K}\left(y_{k}^{\mathrm{s}_{1}}-y_{k}^{\mathrm{s}_{2}}\right)^{2}
$$


Our GRASP procedure uses fixed threshold parameter $\Delta$ and only allows a solution into the archive if its distance to each of the other solutions in the archive (denoted $d_{A}(s)$ ) is at least equal to $\Delta$. The second criterion for addition is that the new solution should outperform its closest neighbour in the archive, $f(s)<f\left(s_{\text {closest }}\right)$. A solution $s$ that is added to the archive replaces $s_{\text {closest }}$, its closest solution in terms of the Hamming distance.

The criteria for addition are overruled in one situation: when the new solution outperforms the best solution found so far during the construction phase. This solution, denoted as $s_{\text {best }}$, is kept in memory at all times and added to the archive at the end of the GRASP-procedure, again replacing its closest archive-solution.

Our GRASP algorithm has four parameters that need to be set: the threshold parameter $\alpha$ that determines the balance between randomness and greediness in the construction phase, the minimal distance from the other solutions in the archive $\Delta$, the maximum number of iterations, and the size of the archive. First of all, we need to set the aforementioned $\alpha$-value to determine the length and composition of the RCL.

The setting of this parameter $\alpha$ determines both the robustness and the quality of the constructed solutions. In order to determine the best possible $\alpha$-value, we performed a pilot study in which we systematically increased the value of this parameter from $\alpha=0$ (completely greedy construction) to $\alpha=1$ (completely random construction) and investigated each of these cases on solution quality (objective value) and solution diversity (average solution distance). Based on the result of this study, $\alpha$ was fixed to 0.4 as for this value the best trade-off between both objectives was found. However, solution quality and diversity do not vary much with changing $\alpha$-values, indicating that our method is rather robust.

Secondly, we also need to specify the degree $\Delta$ to which a solution should differ from all other solutions in the archive in order to be accepted in the archive. This decision is of great importance since it determines to large extent the diversity of the archive and has a large impact on the performance of our local search algorithm, especially its ability to locate different local optima. If we set the minimal distance to a very large value, it becomes very likely that our GRASP-procedure will be unable to find enough solutions that perform better than the unimodal alternative to completely fill the archive. If the value of $\Delta$ is too low, many solutions in the archive will belong to the same basin of attraction and result in the same local optima after local search. The value of $\Delta$ should also take into consideration the number of potential terminal locations.

We have performed a thorough analysis of a selected set of sample of instances, for which we incrementally increased the value of $\Delta$ until it became impossible for the GRASP-algorithm to find sufficiently diverse solutions to fill the archive. The results of these tests are visualized in Figure 3. Based on the results displayed in this figure, we set $\Delta=\lfloor|K| / 4\rfloor$. 


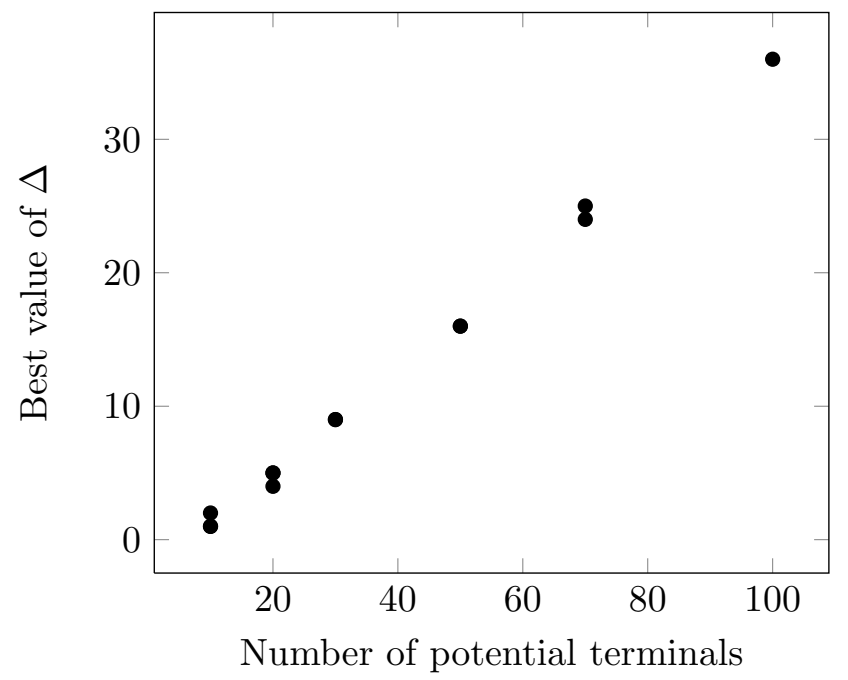

Figure 3: Evaluation of the best value of $\Delta$ (minimal distance to the archive) to achieve high-quality, diverse solutions

For each terminal location $k$, the heuristic therefore maintains two solutions: the best solution found so far in which terminal $k$ is open $\left(S_{k}\right)$ and the best solution found so far in which $k$ is closed $\left(S_{\bar{k}}\right)$. Each time a new solution is generated by adding a terminal, 


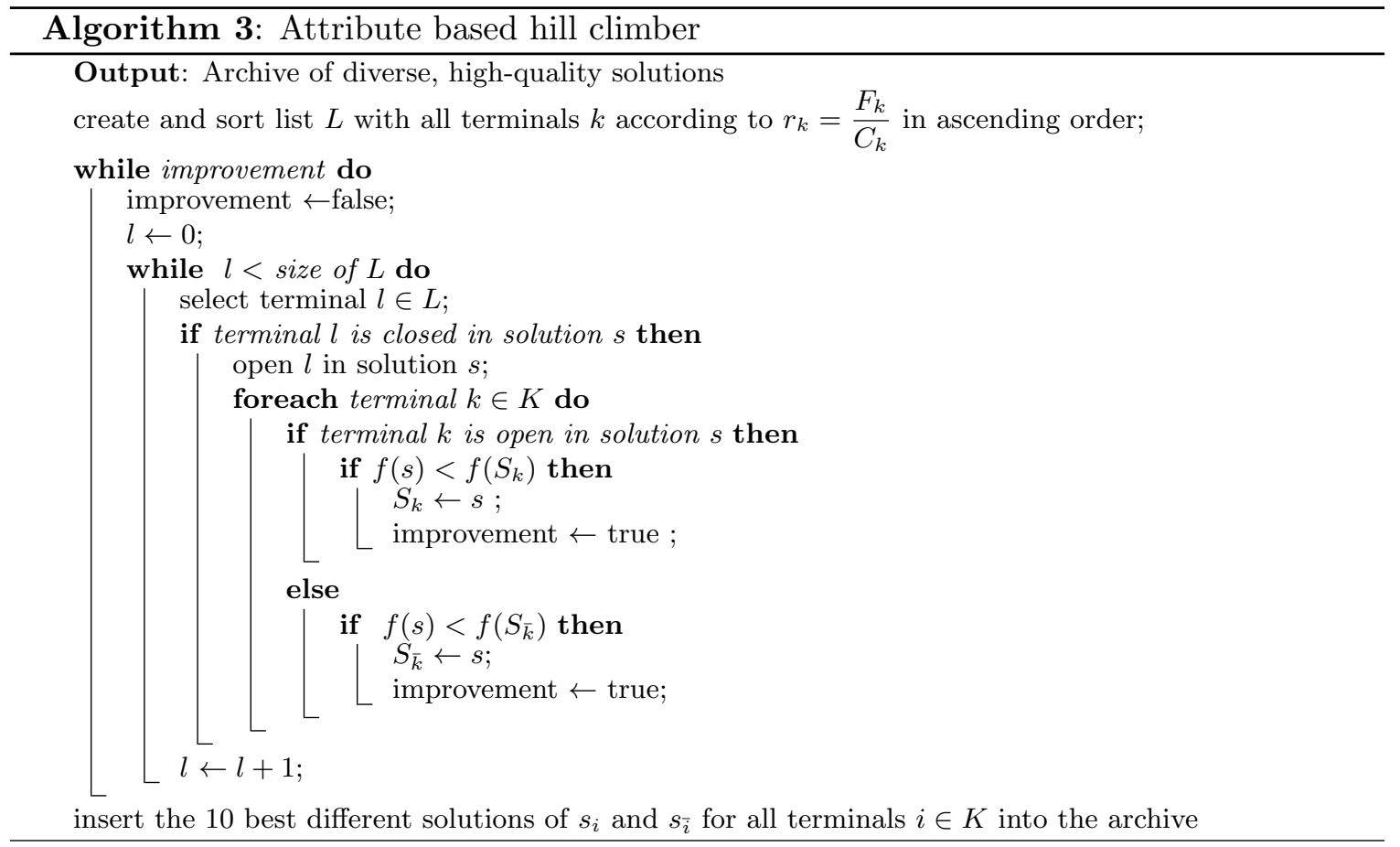

we make the following evaluation for all solution attributes: if terminal $k$ is open in the

newly generated solution and the objective value of the new candidate solution is better than that of $S_{k}$ (the best solution found so far with terminal $k$ open), $S_{k}$ is replaced by the new solution. If terminal $k$ is closed, the comparison should be made with $S_{\bar{k}}$, i.e., the best solution found so far with terminal $k$ closed. If the new solution is worse than both $S_{k}$ and $S_{\bar{k}}$ for all values of $k$, the terminal is closed again.

When all terminals have been either added or not, the ten best, non-duplicate solutions found during the search process are stored in an archive to be further improved later on using local search. In contrast to the GRASP-algorithm, the size of the archive is the only parameter to be set in the ABHC-procedure. Moreover, it is unnecessary to set up a complex archiving mechanism for the $\mathrm{ABHC}$ heuristic since the archive solutions showed to be already sufficiently diverse in nature (see Table 3 ).

\subsection{Improvement phase: ADD and REMOVE local search}

After the construction phase, each solution in the archive is improved by an interchange heuristic that performs a local search on this solution. This local search heuristic consists of 2 steps, called ADD and REMOVE respectively. The first step (ADD) sorts the closed terminals in increasing order of $r_{k}=F_{k} / C_{k}$ and attempts to open each terminal in that 
order. The terminal is opened if this decreases the cost of the solution and then removed from the list of possible terminals to be opened. The REMOVE step on the other hand sorts the open terminals in increasing order of $r_{k}=F_{k} / C_{k}$ and attempts to close each open terminal in this order. The terminal is closed if this decreases the cost of the current solution. At the end of the REMOVE step, the improved solution is added to the archive.

At the end of the improvement phase, the best solution in the archive is returned.

\section{Performance evaluation}

\subsection{Problem instance generation and exact solutions}

Because instances for the intermodal terminal location problem are not available, we have of customers and terminals, in which both the number of customers and the number of terminal locations can vary from 10 to 100 in steps of 10 . The instances can be downloaded from http://antor.ua.ac.be/intermodal.

All instances were solved by implementing the MIP formulation in Eqs. (1-7) in version 410 100 instances in computing times ranging from 0.2 to 872 seconds. All experiments were performed on an Intel(R) Core(TM)2 Quad CPU Q6600 at 2.40GHz with 3.2Gb RAM. 
Detailed results can be found in Table 2 in Appendix B. The first column contains the name of the instance, where $n \mathrm{CmL}$ indicates an instance with $n$ customer and $l$ potential terminal locations.

\subsection{Performance evaluation of the heuristic evaluation procedure}

Assessing the quality of the heuristic evaluation procedure developed for objective value calculation is done on the basis of the Kendall tau rank correlation coefficient $(\tau)$, that measures the correspondence between two rankings and assesses its significance. This coefficient can take on any value between -1 to 1 , where $\tau=1$ corresponds to a situation in which the two rankings are identical and $\tau=-1$ to a situation in which one ranking is exactly the opposite of the other.

We have calculated Kendall's coefficient for 40 of the 100 problem instances. For each of these instances, 1000 random solutions of the master problem are generated in the following way. First, the number of open terminals $n_{r}$ is randomly chosen between 0 and $n$. Next, $n_{r}$ terminals are randomly chosen from the list of possible terminals and opened. The subproblem for these solutions is then solved exactly (using the formulation in Eqs. (8-11)) and heuristically (using the heuristic evaluation procedure). The exact objective functions were calculated using Gurobi 3.0.1. The remaining 60 problem instances were too large for Gurobi to be able to calculate exact objective function values for each number of terminals open, rendering them unusable for the purpose of this section. For each instance the 1000 solutions were ranked according to their exact objective function values and according to their heuristic objective function values and these rankings were compared using Kendall's $\tau$.

435 A correlation coefficient $\tau$ close to 1 is a strong indication that the best solutions are also listed among the best solutions found by the heuristic evaluation procedure. In turn, this would imply that our heuristic evaluation procedure performs well at determining whether a given solution is better than another, an evaluation that has to be made several times during the optimization process. A sample of the results of these calculations can be found in Table 1. A scatter plot of the objective function values and ranks of 1000 solutions for a selected example is shown in Figure 4.

The test results show that - overall- the heuristic evaluation procedure performs well. In some cases however, such as instance 50C10L, Table 1 shows a rather low correlation coefficient. A more detailed analysis of these cases unmasked that they all share the same properties: low terminal prices in combination with a very low ratio of the terminal capacity and the amount of goods to be shipped through the network. In such situations, it is less 
Table 1: Value of Kendall's tau for 1000 randomly generated solutions of selected instances

\begin{tabular}{rccrc}
\hline $\mathbf{C}$ & $\mathbf{L}$ & $\boldsymbol{\tau}$ & \multicolumn{2}{c}{$\boldsymbol{\Delta}_{\max }^{\mathrm{a}}$} \\
\hline 10 & 10 & 0.89 & 22.24 & $\%$ \\
10 & 30 & 0.88 & 20.87 & $\%$ \\
10 & 50 & 0.89 & 20.28 & $\%$ \\
\hline 20 & 10 & 0.84 & 5.15 & $\%$ \\
20 & 30 & 0.88 & 20.75 & $\%$ \\
20 & 50 & 0.89 & 26.17 & $\%$ \\
\hline 30 & 10 & 0.77 & 7.83 & $\%$ \\
30 & 30 & 0.86 & 15.52 & $\%$ \\
30 & 50 & 0.93 & 23.73 & $\%$ \\
\hline 40 & 10 & 0.13 & 3.91 & $\%$ \\
40 & 30 & 0.66 & 10.64 & $\%$ \\
40 & 50 & 0.92 & 18.62 & $\%$ \\
\hline 50 & 10 & 0.13 & 2.79 & $\%$ \\
50 & 30 & 0.49 & 8.60 & $\%$ \\
50 & 50 & 0.10 & 7.93 & $\%$ \\
\hline
\end{tabular}

a Difference between the exact objective function values best and the worst solution of 1000 random solutions
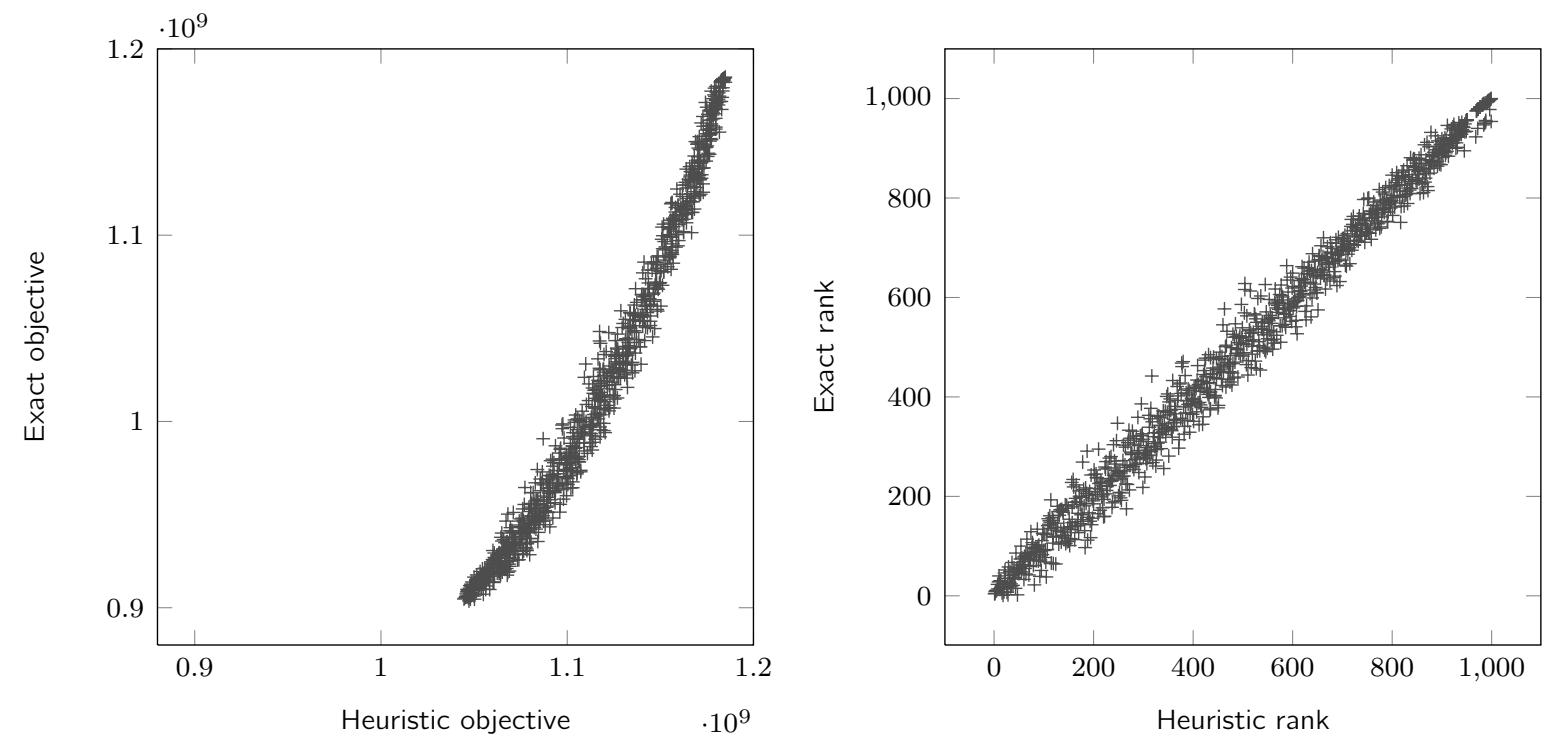

Figure 4: Scatter plots of exact versus heuristic objective function value (left) and exact versus heuristic rank (right) of 1000 solutions, instance 20 customers, 50 potential terminal locations 
important which terminals are opened as (1) opening terminals is cheap and (2) only a fraction of the demand will be shipped by intermodal transport anyway (because of the low terminal capacity). Consequently, for these cases, the objective value of any solution will not deviate much from that of the optimal solution, i.e., in these cases almost all solutions are good solutions. Indeed, Table 1 indicates that the absolute difference between the worst possible solution and the best is very small in these cases. Therefore, despite a low $\tau$, this evaluation method still allows the overall metaheuristic to make good decisions.

Finally, it should be noted that there can be significant deviations between the exact and the heuristic objective function value of a solution, even for problem instances where the value of $\tau$ is close to 1 . The high value of $\tau$ means that the heuristic will in most cases correctly judge whether one solution of the master problem is better than another, although it may be preferable to use a slower heuristic to solve the subproblem (assign demands to terminals) for the final solution of the master problem.

\subsection{Metaheuristics performance evaluation}

In this section, we try to formulate an answer to the question which of the two initial construction phases (GRASP and ABHC) achieves best performance. The test results are summarized and interpreted. For more detailed test results, we refer to Tables 3,4 and 5 in Appendix C.

In a first phase, we allow both solution construction methods the same computing time. Since the ABHC has a natural stopping criterion, we allow the GRASP-procedure to run exactly as long as the ABHC method $\left(\operatorname{GRASP}_{a}\right)$. We first compare the archive of both methods in terms of solution quality and diversity before local search. If the solutions in the archive are already of high quality at this point, it will take the local search algorithm less time to reach a local optimum. Additionally, the more diverse the solutions in the archive, the more local optima can be found by the local search improvement heuristic and the greater the probability of reaching the global optimum.

The solution quality is evaluated by comparing the objective function value of the best solution in the archive of both methods. To compare the solution diversity in the archive, we compare the average of all average distances of each solution to all other solutions in the archive. The results of these calculations can be found in Figures 5 and 6 . From these figures, it is clear that - at least before the local search phase - the ABHC-algorithm strongly outperforms the $\mathrm{GRASP}_{a}$-algorithm on both parameters.

We make a similar comparison after local search but now in terms of solution quality and computing time. The results of these experiments can be found in Figures 7 and 8 


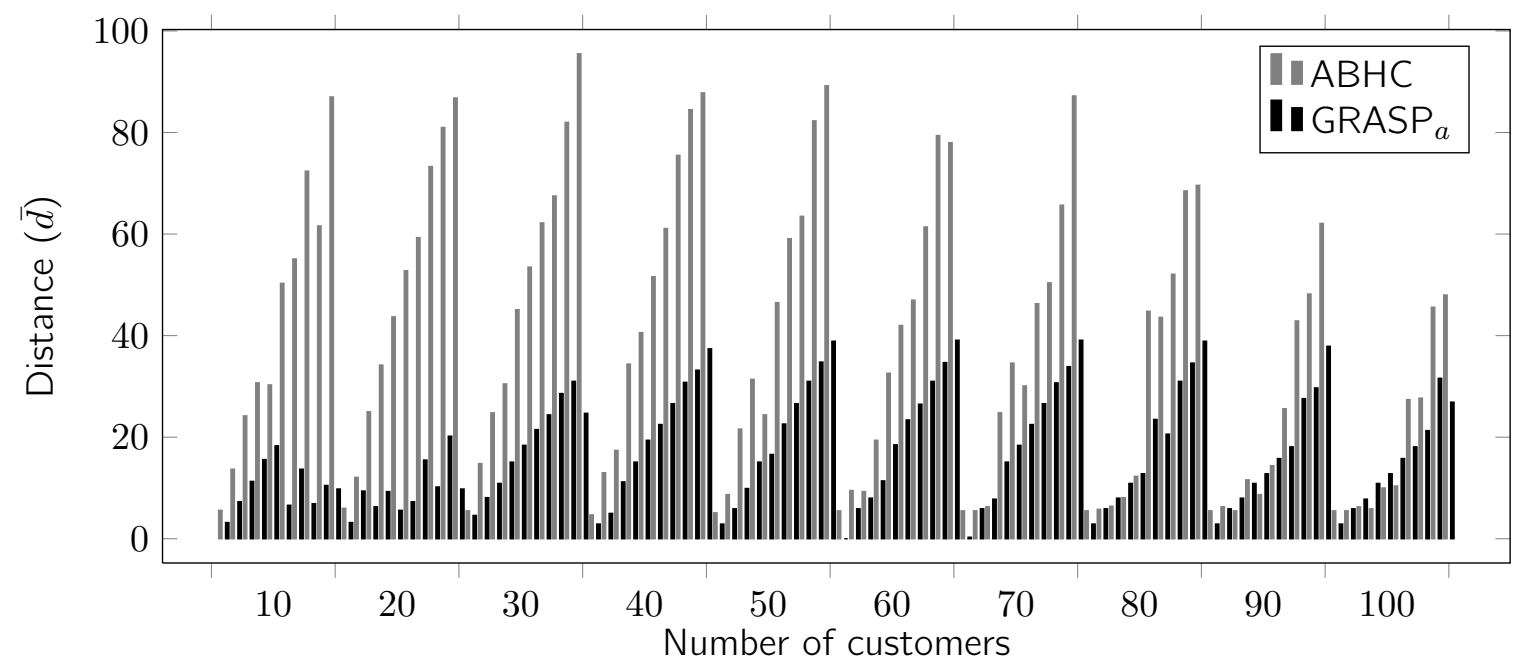

Figure 5: Average distances to all other solutions of solutions in the archive generated during the construction phase by ABHC and GRASP

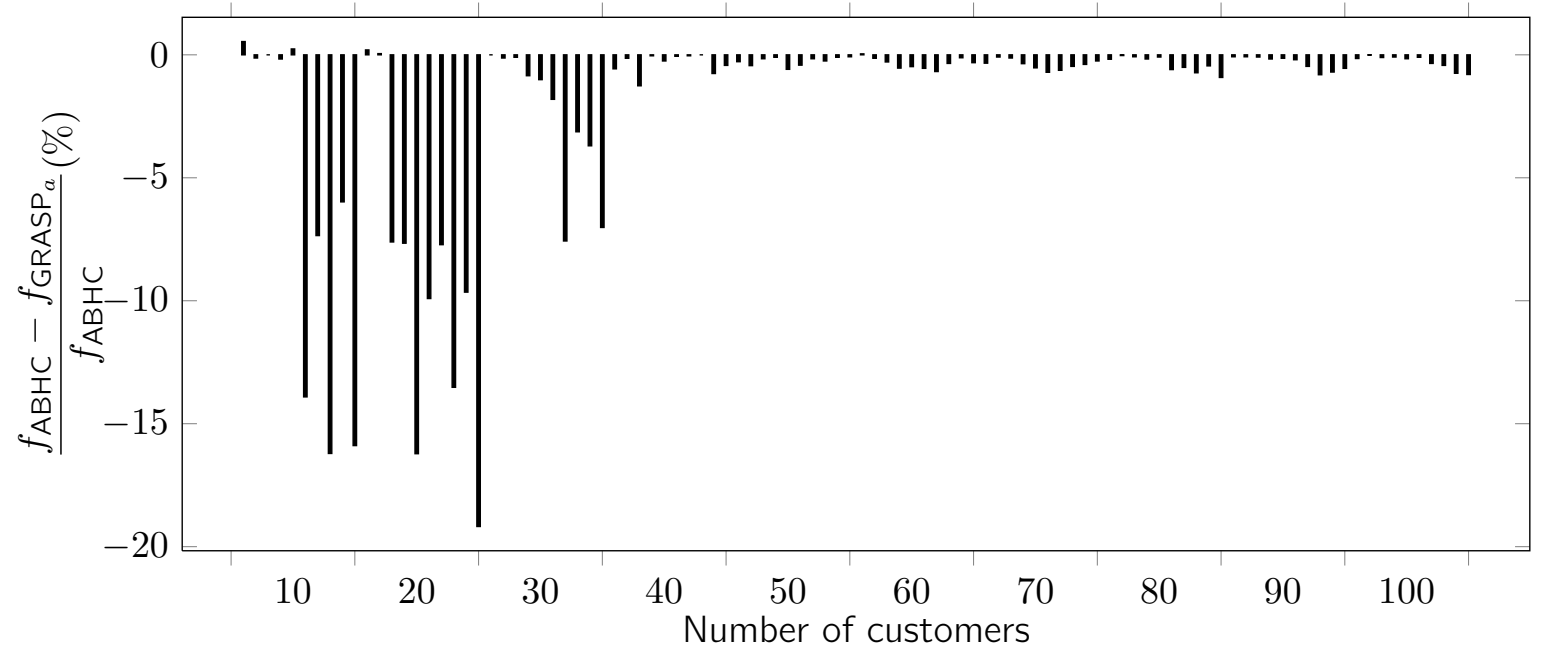

Figure 6: Relative deviation of the best solution in the archive generated by $\mathrm{GRASP}_{a}$ from the best solution in the archive generated by $\mathrm{ABHC}$ (negative values indicate that the solution found by $\mathrm{ABHC}$ is better) 
$\left(\operatorname{GRASP}_{a}\right)$. As can be seen from Figure 7 , in which we report the quality of the best solution found by applying the local search heuristic to each of the solutions in the archive, the performance of our metaheuristic using $\mathrm{GRASP}_{a}$ is on par with that using ABHC. In this case, the solution quality gap between both methods becomes almost non-existent, outliers have disappeared and the number of cases in which GRASP performs better than $\mathrm{ABHC}$ is more or less equal to the number of cases in which $\mathrm{ABHC}$ outperforms $\operatorname{GRASP}_{a}$.

The question is now raised whether this conclusion still holds if the running time of the GRASP algorithm is extended, and hence is no longer limited to the running time of the ABHC-procedure. When more time is available, the solutions produced by GRASP can be further improved by adjusting some of the GRASP-parameters. In fact, by increasing the number of iterations or setting the $\alpha$-value closer to 1, i.e., closer to complete randomness, the GRASP-algorithm can explore larger parts of the solution space and consequently higher its chances of finding the optimal solution. Keeping the $\alpha$ value unchanged, Figures 7 and 8 $\left(\right.$ GRASP $\left._{b}\right)$ display the results of the GRASP algorithm that was able to run until no further improvement was found for 10 iterations. This graph shows no sufficient improvement in solution quality to compensate for the longer calculation times.

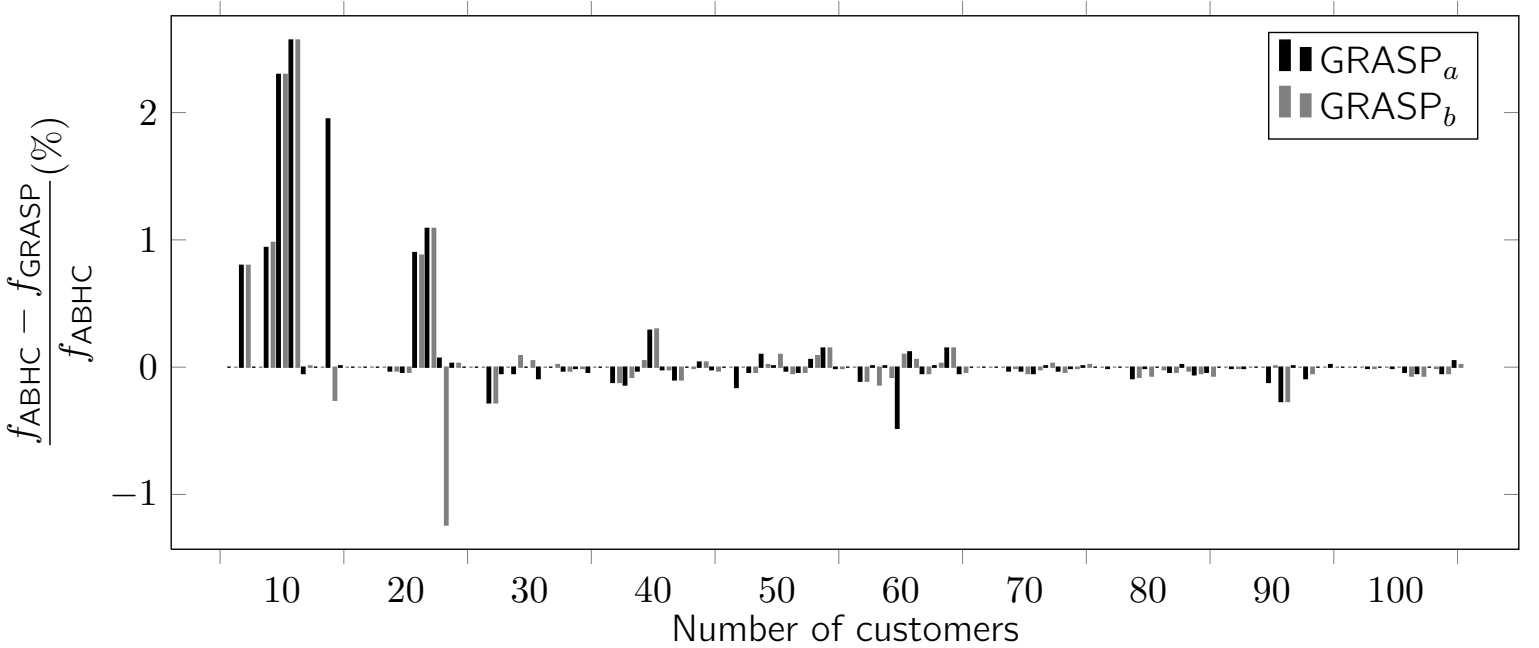

Figure 7: Relative deviation of the best solution found after local search using GRASP and ABHC during the construction phase (negative values indicate that the solution found when using $A B H C$ is better)

It can be concluded from the previous analysis that there is no real difference in performance between the two metaheuristics developed in this paper. In a very short amount of time, they both provide the decision maker with high-quality solutions that do not deviate much in objective value from the exact solutions. The results of comparing the objective value of the best solutions generated by the heuristics and the optimal solutions are visualized in Figure 9. In fact, the largest relative difference in total cost between the exact method 


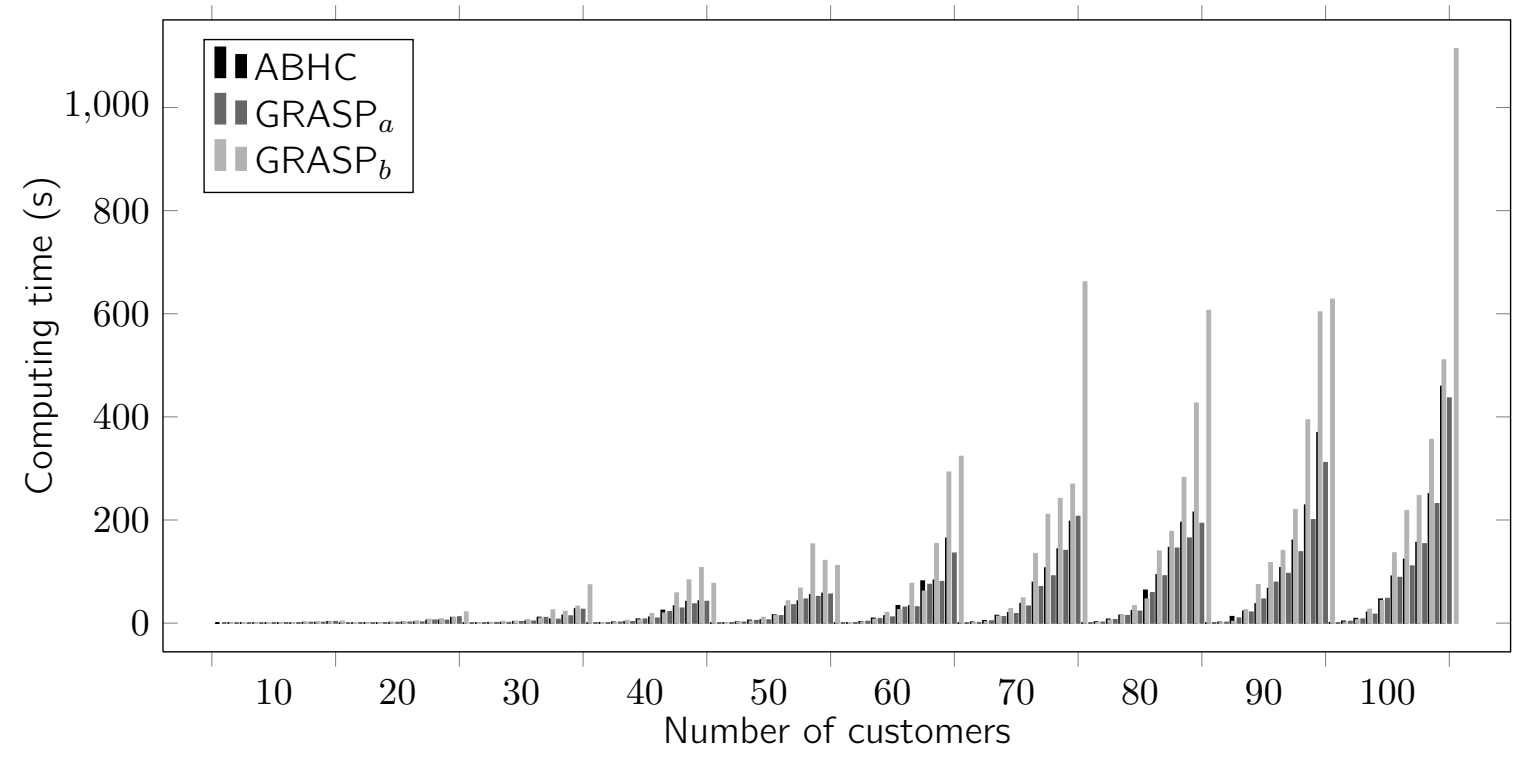

Figure 8: CPU times of $\mathrm{ABHC}$ and GRASP

and the metaheuristics using either $\mathrm{ABHC} \mathrm{GRASP}_{a}$ and $\mathrm{GRASP}_{b}$ during the construction phase amounted to no more than $2.75 \%, 4.1 \%$ and $3.61 \%$ respectively. One argument in favor of using ABHC during the construction phase is that it is parameter-free. By avoiding the parametric discussion, this method is more transparent and hence more likely to be easily accepted by its users.

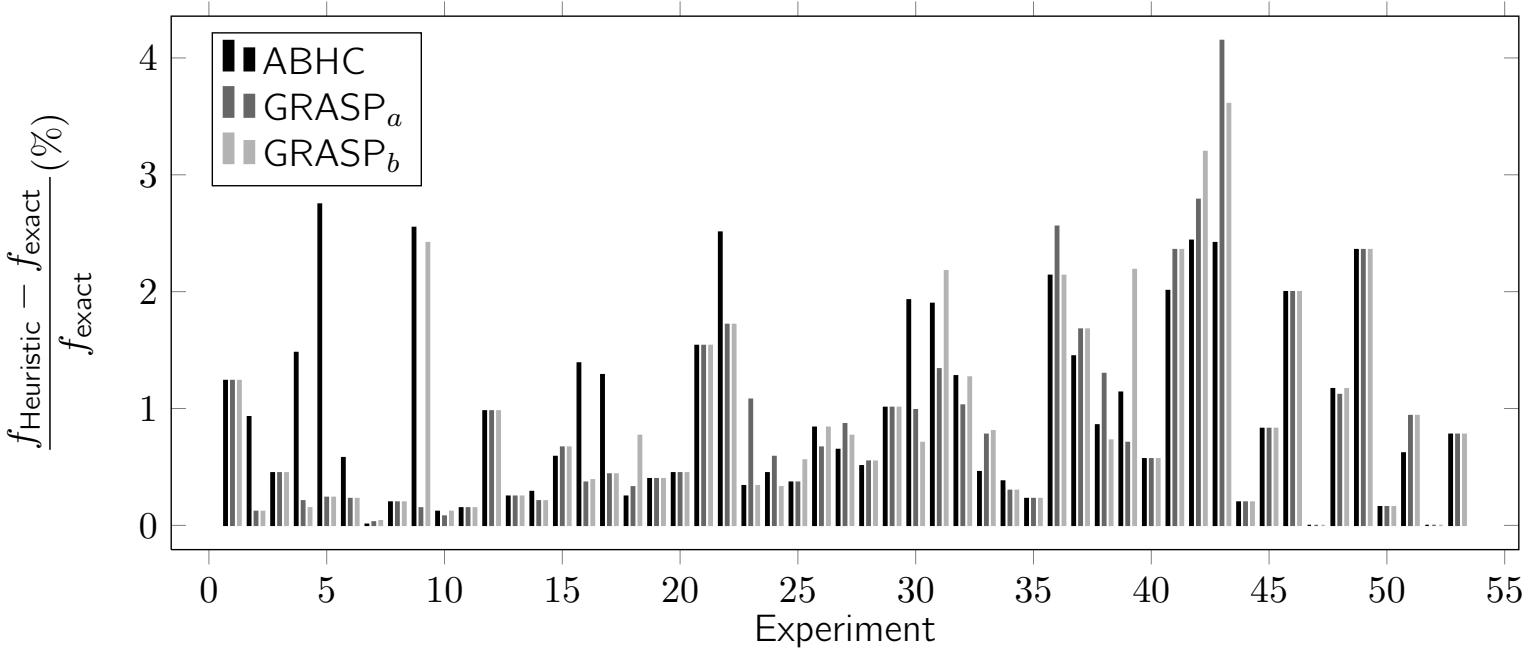

Figure 9: Relative deviation of the best solution found by the heuristics from the optimal solution 


\section{Conclusion and future research}

The low level of maturity in intermodal transportation can be explained to a large extent transportation modes proves to be a large drawback in practice, resulting in high transit times and cost. Intermodal transshipment terminals play an essential role in enhancing the connectivity between modes and hence in improving the attractiveness of intermodal transportation in general.

In order to determine the optimal number and location of transshipment terminals in an intermodal network, two different metaheuristics have been developed that both consist out of two phases: a construction heuristic to build solutions, and a local search algorithm to improve solutions. The proposed methods only differ in terms of the applied construction heuristic: whereas the first method makes use of the GRASP metaheuristic, the second uses the relatively unknown ABHC (attribute based hill climber) instead. To allow the method to solve arbitrarily large instances in reasonable computing times, we have additionally developed a heuristic evaluation procedure to calculate a good approximation of the objective function value in a short computing time.

The main purpose of this paper was to investigate which of the two methods performs best at solving real-life sized instances of the intermodal terminal location problem. Our numerical results show however that both methods generate equally good solutions that approximate the optimal solution very closely. From a user perspective, one could argue that the ABHC heuristic should be preferred because it is parameter-free. Either way, our tests clearly prove the usefulness and value of metaheuristics for solving real-life problems that are too complex to be solved to optimality.

We conclude this paper with a couple of recommendations for further refinement of our approach and future research. Although increasing the number of iterations of the GRASPalgorithm had no significant impact on the solution quality, it remains interesting to investigate what the effect of further optimization of the GRASP parameter setting would be, for example by using techniques such as experimental design. The surplus time and effort that an in-depth parametric analysis demands, might not be justifiable for the time being, i.e., the tool serves as a trigger for discussion, but this attitude might change in the future when intermodalism would have achieved a higher level of maturity and the tool would indeed be used for determining the actual location of new intermodal terminals. Additionally, given the number of stakeholders involved in this problem and the impact on society of transportation in general, it is likely that our objective function, i.e., minimizing the total cost, is too simple to reflect reality and that the problem at hand should be transformed 
in a multi-objective one. In this way, the fixed cost for locating terminals could be split off from the variable transportation cost. An even more interesting alternative is to extend the objective function to incorporate other decision criteria such as environmental impact.

\section{A. Complexity of the intermodal terminal location problem}

Theorem 1. The intermodal terminal location problem in Eqs. (1-7) is NP-hard.

Proof. This result follows from the fact that the intermodal terminal location problem is an extension of the capacitated facility location problem, a known NP-hard problem. We show this by demonstrating that each instance of the CFLP can be converted to a corresponding instance of the intermodal terminal location problem in polynomial time.

Assume an instance of the CFLP with a set of customers $I_{o}$ and a set of potential facilities $K_{o}$. Each facility $k \in K_{o}$ has a fixed cost $\hat{F}_{k}$ and a capacity $\hat{C}_{k}$. Each customer $i \in I_{o}$ has a demand $\hat{q}_{i}$ that has to be delivered from one or more of the facilities. The cost of transporting one unit of demand from facility $k$ to customer $i$ is equal to $\hat{c}_{i}^{k}$. If we define variables $x_{i}^{k}$ to be the demand transported from facility $k$ to customer $i$ and $y_{k}$ the binary variable that is equal to 1 if facility $k$ is used and zero otherwise, the mathematical formulation of this problem is the following.

$$
\begin{aligned}
& \min \sum_{i \in I_{o}} \sum_{k \in K_{o}} \hat{c}_{i}^{k} x_{i}^{k}+\sum_{k \in K_{o}} \hat{F}_{k} y_{k} \\
& \text { s.t. } \\
& \quad x_{i}^{k} \leqslant \hat{q}_{i} y_{k} \\
& \quad \sum_{k \in K_{o}} x_{i}^{k}=\hat{q}_{i} \\
& \quad \sum_{i \in I_{o}} x_{i}^{k} \leqslant \hat{C}_{k} \\
& \quad x_{i}^{k} \geqslant 0 \\
& y_{k} \in\{0,1\}
\end{aligned}
$$

We show that this instance of the CFLP can be transformed into an instance of the in-

termodal terminal location problem. For each customer $i$ in the CFLP, we create two customers in the intermodal terminal location instance, an origin customer $i$ and a destination customer $\delta(i)(\delta($.$) is a function that returns the index of the destination customer$ 
corresponding to the origin customer in its argument). The demand to be transported from customer $i$ to customer $\delta(i)$ is set to equal the demand of customer $i$ in the CFLP instance, i.e., $q_{i \delta(i)} \equiv \hat{q}_{i}$. The demand from customer $\delta(i)$ to customer $i$ is also set to zero $\left(q_{\delta(i) i} \equiv 0\right)$, as well as all other demands between customers not descendent from the same customer in the CFLP, i.e., $q_{i \delta j} \equiv 0, \forall j \neq i$.

For each facility $k$ in the CFLP, we create an origin and a destination terminal $k$ and $\Delta(k)$ in the intermodal terminal location instance $(\Delta($.$) is a function that returns the destination$ terminal corresponding to the origin terminal in its argument) and set the capacity of these terminals both equal to the capacity of facility $k$ in the CFLP, i.e., $C_{k} \equiv C_{\Delta(k)} \equiv \hat{C}_{k}$. The fixed cost of locating terminals $k$ and $\Delta(k)$ is set to half the fixed cost of locating facility $k$ in the CFLP, i.e., $F_{k} \equiv F_{\Delta(k)} \equiv \hat{F}_{k} / 2$. The cost of transporting a unit of demand from customer $i$ to customer $\delta(i)$ through terminals $k$ and $\Delta(k)$ is set equal to the cost of delivering a unit of demand from facility $k$ to customer $i$ in the CFLP, i.e., $c_{i \delta(i)}^{k \Delta(k)} \equiv \hat{c}_{i}^{k}$. All other transportation costs, i.e., the cost of delivering demand between customers not descendent from the same customer in the CFLP, as well as the unimodal costs between any pair of customers $c_{i j}$, are set to infinity.

From the above it follows that any optimal solution of the intermodal terminal location instance created in this way will have the following properties. First, transportation variables $x_{i j}^{k m}$ will be zero if transportation is not from an origin to a destination customer corresponding to the same customer in the CFLP, using an origin and a destination terminal corresponding to the same facility. Also, all unimodal demand variables $w_{i j}$ will be zero in the optimal solution. In other words, the only variables $x_{i j}^{k m}$ that will be non-zero in 585 the optimal solution are of the form $x_{i \delta(i)}^{k \Delta(k)}$. Since demand can only be shipped through terminals $k$ and $\Delta(k)$ if both are open, it follows that -in the optimal solution-terminals will only be opened in pairs. Opening an origin terminal without opening the corresponding destination terminal will only incur a cost without allowing any transportation. Therefore, in the optimal solution, $y_{k}=y_{\Delta(k)}$.

590 The mathematical formulation of the intermodal terminal location problem in Eqs. (1-7) for the instance generated using this special structure can thus be written as follows. 


$$
\min \sum_{i \in I_{o}} \sum_{k \in K_{o}} c_{i \delta(i)}^{k \Delta(k)} x_{i \delta(i)}^{k \Delta(k)}+\sum_{k \in K_{o}} F_{k}\left(y_{k}+y_{\Delta(k)}\right)
$$

s.t.

$$
\begin{aligned}
& x_{i \delta(i)}^{k \Delta(k)} \leqslant q_{i \delta(i)} y_{k} \\
& x_{i \delta(i)}^{k \Delta(k)} \leqslant q_{i \delta(i)} y_{k \Delta(k)} \\
& \sum_{k \in K_{o}} x_{i \delta(i)}^{k \Delta(k)}=q_{i \delta(i)} \\
& \sum_{i \in I_{o}} \sum_{k \in K_{o}} x_{i \delta(i)}^{k \Delta(k)} \leqslant C_{k} \\
& x_{i \delta(i)}^{k \Delta(k)} \geqslant 0 \\
& y_{k}, y_{\delta(k)} \in\{0,1\}
\end{aligned}
$$

$\forall k \in K_{o}$

$\forall k \in K_{o}$

$\forall i \in I_{o}$

$\forall k \in K_{o}$

$\forall i \in I_{o}, \forall k \in K_{o}$

$\forall k \in K_{o}$

Since $y_{\Delta(k)} \equiv y_{k}$ in the optimal solution, Eq. (21) is redundant. If we now make the following substitutions: $x_{i \delta(i)}^{k \Delta(k)} \rightarrow x_{i}^{k}, y_{\Delta(k)} \rightarrow y_{k}, c_{i \delta(i)}^{k \Delta(k)} \rightarrow \bar{c}_{i}^{k}, q_{i \delta(i)} \rightarrow \bar{q}_{i}, C_{k} \rightarrow \bar{C}_{k}, F_{k} \rightarrow \bar{F}_{k} / 2$, we obtain the formulation of the CFLP instance that was converted to an intermodal location problem instance.

We have shown that the CFLP is a special case of the intermodal terminal location problem.

Therefore, since the CFLP is NP hard, so is the intermodal terminal location problem.

\section{B. Exact solutions}

Table 2: Exact solutions found by Gurobi 3.0.1

\begin{tabular}{lcrlcrr}
\hline Instance & Cost $\left(\times 10^{7}\right)$ & Time $(\mathrm{s})$ & & Instance & Cost $\left(\times 10^{7}\right)$ & Time $(\mathrm{s})$ \\
\cline { 1 - 2 } 10C10L & 9.5403 & 0.2 & & 30C80L & 75.126 & 440.9 \\
10C20L & 9.0838 & 0.8 & & 40C10L & 206.73 & 8.8 \\
10C30L & 9.1671 & 1.9 & & 40C20L & 203.40 & 56.3 \\
10C40L & 8.8075 & 4.7 & & 40C30L & 205.42 & 116.7 \\
10C50L & 8.3906 & 6.1 & 40C40L & 171.06 & 7.9 \\
10C60L & 7.4758 & 9.2 & 40C50L & 181.93 & 359.1 \\
10C70L & 7.6379 & 15.0 & & 40C60L & 170.94 & 629.1 \\
10C80L & 7.9555 & 24.7 & 50C10L & 334.25 & 8.8 \\
10C90L & 8.6786 & 30.2 & 50C20L & 300.56 & 45.0 \\
10C100L & 8.3989 & 43.3 & & 50C30L & 285.78 & 134.1 \\
20C10L & 50.916 & 1.0 & & 50C40L & 286.97 & 318.7 \\
20C20L & 45.968 & 6.9 & 50C50L & 262.46 & 481.3 \\
20C30L & 46.358 & 14.0 & 60C10L & 437.13 & 13.4 \\
20C40L & 40.123 & 33.6 & 60C20L & 440.60 & 88.1 \\
20C50L & 34.403 & 56.8 & 60C30L & 421.14 & 677.0 \\
20C60L & 41.174 & 69.3 & 60C40L & 426.65 & 677.8
\end{tabular}




\begin{tabular}{lcrlrr} 
20C70L & 33.559 & 83.5 & 70C10L & 633.54 & 19.1 \\
20C80L & 36.024 & 248.0 & 70C20L & 613.96 & 152.0 \\
20C90L & 32.626 & 299.3 & 70C30L & 581.41 & 460.0 \\
20C100L & 38.512 & 389.9 & 80C10L & 778.89 & 23.1 \\
30C10L & 111.66 & 2.8 & 80C20L & 821.40 & 232.0 \\
30C20L & 104.16 & 11.6 & 80C30L & 782.35 & 872.0 \\
30C30L & 103.31 & 45.7 & 90C10L & 1054.3 & 54.9 \\
30C40L & 80.470 & 0.7 & 90C20L & 1036.5 & 220.2 \\
30C50L & 89.726 & 146.9 & 100C10 & 1319.9 & 75.4 \\
30C60L & 88.521 & 209.3 & 100C20 & 1276.2 & 675.7 \\
30C70L & 90.509 & 535.7 & & & \\
\hline
\end{tabular}

\section{Comparison of metaheuristics}

Table 3: Results of the metaheuristic with $\mathrm{ABHC}$ construction phase

\begin{tabular}{|c|c|c|c|c|c|c|c|c|c|}
\hline \multirow[b]{2}{*}{ Instance } & \multicolumn{4}{|c|}{ ABHC } & \multicolumn{3}{|c|}{ ABHC + Local Search } & \multicolumn{2}{|c|}{ Evaluation } \\
\hline & $\begin{array}{l}\text { exact }^{1} \\
\left(\times 10^{7}\right)\end{array}$ & $\begin{array}{c}\text { approx. }^{2} \\
\left(\times 10^{7}\right)\end{array}$ & $\bar{d}^{3}$ & $\begin{array}{l}\mathrm{CPU} \\
(\mathrm{s})\end{array}$ & $\begin{array}{l}\text { exact }^{4} \\
\left(\times 10^{7}\right)\end{array}$ & $\begin{array}{l}\text { approx. }^{5} \\
\left(\times 10^{7}\right)\end{array}$ & $\begin{array}{l}\mathrm{CPU} \\
(\mathrm{s})\end{array}$ & speedup $^{6}$ & $\begin{array}{c}\operatorname{dev}^{7} \\
(\%)\end{array}$ \\
\hline $10 \mathrm{C} 10 \mathrm{~L}$ & 9.7166 & 10.105 & 5.6 & 0.01 & 9.6586 & 10.049 & 0.01 & 24.0 & $1.24 \%$ \\
\hline $10 \mathrm{C} 20 \mathrm{~L}$ & 9.2236 & 9.2283 & 13.7 & 0.01 & 9.1684 & 9.1752 & 0.01 & 88.0 & $0.93 \%$ \\
\hline $10 \mathrm{C} 30 \mathrm{~L}$ & 9.3541 & 9.6471 & 24.2 & 0.01 & 9.2081 & 9.5157 & 0.02 & 99.5 & $0.45 \%$ \\
\hline $10 \mathrm{C} 40 \mathrm{~L}$ & 8.9840 & 9.0989 & 30.7 & 0.01 & 8.9382 & 9.0661 & 0.04 & 118.3 & $1.48 \%$ \\
\hline $10 \mathrm{C} 50 \mathrm{~L}$ & 8.6010 & 8.9194 & 30.3 & 0.01 & 8.6209 & 8.9134 & 0.05 & 123.6 & $2.75 \%$ \\
\hline $10 \mathrm{C} 60 \mathrm{~L}$ & 7.7108 & 7.8456 & 50.3 & 0.01 & 7.5190 & 7.8316 & 0.06 & 154.5 & $0.58 \%$ \\
\hline $10 \mathrm{C} 70 \mathrm{~L}$ & 7.8425 & 7.8622 & 55.1 & 0.03 & 7.6385 & 7.6928 & 0.07 & 215.1 & $0.01 \%$ \\
\hline $10 \mathrm{C} 80 \mathrm{~L}$ & 8.1432 & 8.2461 & 72.4 & 0.06 & 7.9713 & 8.0759 & 0.13 & 190.6 & $0.20 \%$ \\
\hline 10C90L & 8.9229 & 8.9484 & 61.6 & 0.05 & 8.8999 & 8.8990 & 0.13 & 232.9 & $2.55 \%$ \\
\hline $10 \mathrm{C} 100 \mathrm{~L}$ & 8.6226 & 8.7324 & 87.0 & 0.09 & 8.4088 & 8.5228 & 0.19 & 228.4 & $0.12 \%$ \\
\hline $20 \mathrm{C} 10 \mathrm{~L}$ & 51.236 & 51.664 & 6.0 & 0.01 & 50.991 & 51.420 & 0.01 & 109.0 & $0.15 \%$ \\
\hline $20 \mathrm{C} 20 \mathrm{~L}$ & 46.118 & 51.781 & 12.1 & 0.01 & 46.419 & 51.559 & 0.12 & 58.3 & $0.98 \%$ \\
\hline $20 \mathrm{C} 30 \mathrm{~L}$ & 46.643 & 51.725 & 25.0 & 0.03 & 46.472 & 51.573 & 0.23 & 65.1 & $0.25 \%$ \\
\hline $20 \mathrm{C} 40 \mathrm{~L}$ & 40.365 & 44.363 & 34.2 & 0.06 & 40.238 & 44.127 & 0.50 & 67.3 & $0.29 \%$ \\
\hline $20 \mathrm{C} 50 \mathrm{~L}$ & 34.956 & 36.893 & 43.7 & 0.08 & 34.605 & 36.601 & 0.30 & 189.6 & $0.59 \%$ \\
\hline $20 \mathrm{C} 60 \mathrm{~L}$ & 41.798 & 44.191 & 52.8 & 0.12 & 41.745 & 44.147 & 0.42 & 165.2 & $1.39 \%$ \\
\hline $20 \mathrm{C} 70 \mathrm{~L}$ & 34.238 & 36.496 & 59.3 & 0.17 & 33.992 & 36.388 & 0.67 & 124.8 & $1.29 \%$ \\
\hline $20 \mathrm{C} 80 \mathrm{~L}$ & 36.674 & 38.392 & 73.3 & 0.30 & 36.114 & 37.859 & 0.73 & 340.3 & $0.25 \%$ \\
\hline $20 \mathrm{C} 90 \mathrm{~L}$ & 33.359 & 35.330 & 81.0 & 0.34 & 32.756 & 34.737 & 0.84 & 356.4 & $0.40 \%$ \\
\hline $20 \mathrm{C} 100 \mathrm{~L}$ & 39.157 & 40.735 & 86.8 & 0.49 & 38.685 & 40.192 & 1.10 & 354.5 & $0.45 \%$ \\
\hline $30 \mathrm{C} 10 \mathrm{~L}$ & 111.66 & 117.71 & 5.5 & 0.01 & 113.37 & 117.67 & 0.02 & 138.0 & $1.54 \%$ \\
\hline $30 \mathrm{C} 20 \mathrm{~L}$ & 104.46 & 113.35 & 14.8 & 0.03 & 106.78 & 112.90 & 0.26 & 44.7 & $2.51 \%$ \\
\hline $30 \mathrm{C} 30 \mathrm{~L}$ & 103.53 & 116.91 & 24.8 & 0.11 & 103.66 & 116.76 & 1.13 & 40.4 & $0.34 \%$ \\
\hline $30 \mathrm{C} 40 \mathrm{~L}$ & 81.260 & 90.544 & 30.5 & 0.14 & 80.829 & 90.188 & 1.09 & 63.9 & $0.45 \%$ \\
\hline $30 \mathrm{C} 50 \mathrm{~L}$ & 90.461 & 104.42 & 45.1 & 0.30 & 90.055 & 104.07 & 2.50 & 58.8 & $0.37 \%$ \\
\hline $30 \mathrm{C} 60 \mathrm{~L}$ & 89.637 & 101.40 & 53.5 & 0.37 & 89.268 & 101.02 & 2.77 & 75.6 & $0.84 \%$ \\
\hline $30 \mathrm{C} 70 \mathrm{~L}$ & 91.368 & 105.53 & 62.2 & 0.93 & 91.095 & 105.42 & 6.85 & 78.2 & $0.65 \%$ \\
\hline
\end{tabular}

${ }^{1}$ Exact objective function value of the best solution in the archive (NA: problem too large to solve exactly).

${ }^{2}$ Heuristic objective function value of the best solution in the archive.

${ }^{3}$ Average of all average distances of each solution in the archive to all other archive-solutions.

${ }^{4}$ Exact objective function value of the best solution after local search (NA: problem too large to solve exactly).

${ }^{5}$ Heuristic objective function value of the best solution after local search.

${ }^{6}$ Number of times the metaheuristic is faster than the exact method (ratio of exact method CPU time to metaheuristic CPU time).

${ }^{7}$ Deviation from the optimal solution (value of the exact objective function value of the best solution after local search (column 6) minus objective function value of the optimal solution (see Table 2) divided by the latter). 


\begin{tabular}{|c|c|c|c|c|c|c|c|c|c|}
\hline 30C80L & 76.087 & 85.868 & 67.5 & 0.68 & 75.509 & 85.372 & 4.07 & 108.3 & $0.51 \%$ \\
\hline 30C90L & 86.931 & 98.448 & 82.0 & 1.18 & 86.228 & 97.822 & 7.26 & NA & NA \\
\hline $30 \mathrm{C} 100 \mathrm{~L}$ & NA & 98.864 & 95.5 & 1.97 & 88.075 & 98.382 & 6.83 & NA & NA \\
\hline 40C10L & 208.81 & 211.72 & 4.7 & 0.01 & 208.81 & 211.72 & 0.07 & 125.9 & $1.01 \%$ \\
\hline $40 \mathrm{C} 20 \mathrm{~L}$ & 207.61 & 219.44 & 13.0 & 0.06 & 207.32 & 219.21 & 0.69 & 81.6 & $1.93 \%$ \\
\hline $40 \mathrm{C} 30 \mathrm{~L}$ & 209.14 & 224.13 & 17.4 & 0.21 & 209.32 & 224.00 & 2.98 & 39.2 & $1.90 \%$ \\
\hline 40C40L & 171.27 & 193.26 & 34.4 & 0.32 & 173.24 & 193.06 & 2.91 & 64.6 & $1.28 \%$ \\
\hline 40C50L & 182.75 & 211.85 & 40.6 & 0.81 & 182.76 & 211.82 & 12.13 & 29.6 & $0.46 \%$ \\
\hline $40 \mathrm{C} 60 \mathrm{~L}$ & 171.96 & 196.05 & 51.6 & 1.06 & 171.58 & 195.92 & 10.08 & 62.4 & $0.38 \%$ \\
\hline 40C70L & 178.10 & 210.51 & 61.1 & 2.26 & 177.52 & 210.01 & 24.33 & NA & NA \\
\hline $40 \mathrm{C} 80 \mathrm{~L}$ & NA & 197.64 & 75.5 & 3.23 & NA & 197.48 & 32.49 & NA & NA \\
\hline 40C90L & NA & 176.15 & 84.5 & 3.32 & NA & 175.85 & 30.63 & NA & NA \\
\hline $40 \mathrm{C} 100 \mathrm{~L}$ & NA & 176.37 & 87.8 & 3.57 & NA & 175.78 & 31.98 & NA & NA \\
\hline $50 \mathrm{C} 10 \mathrm{~L}$ & 334.61 & 339.52 & 5.1 & 0.02 & 335.03 & 339.50 & 0.17 & 52.2 & $0.23 \%$ \\
\hline $50 \mathrm{C} 20 \mathrm{~L}$ & 307.93 & 314.67 & 8.7 & 0.10 & 307.00 & 314.53 & 0.86 & 53.4 & $2.14 \%$ \\
\hline $50 \mathrm{C} 30 \mathrm{~L}$ & 288.59 & 308.70 & 21.6 & 0.24 & 289.93 & 308.03 & 2.38 & 56.4 & $1.45 \%$ \\
\hline $50 \mathrm{C} 40 \mathrm{~L}$ & 290.10 & 319.91 & 31.4 & 0.57 & 289.44 & 319.57 & 5.49 & 58.1 & $0.86 \%$ \\
\hline $50 \mathrm{C50L}$ & 267.41 & 285.37 & 24.4 & 0.70 & 265.45 & 283.69 & 6.68 & 72.1 & $1.14 \%$ \\
\hline $50 \mathrm{C} 60 \mathrm{~L}$ & 254.38 & 290.99 & 46.5 & 1.52 & 254.04 & 290.55 & 16.52 & NA & NA \\
\hline $50 \mathrm{C} 70 \mathrm{~L}$ & NA & 306.05 & 59.1 & 3.24 & NA & 305.96 & 39.03 & NA & NA \\
\hline 50C80L & NA & 300.34 & 63.5 & 4.22 & NA & 300.34 & 71.30 & NA & NA \\
\hline 50C90L & NA & 295.87 & 82.3 & 4.94 & NA & 295.87 & 98.75 & NA & NA \\
\hline $50 \mathrm{C} 100 \mathrm{~L}$ & NA & 271.24 & 89.2 & 5.55 & NA & 270.39 & 56.91 & NA & NA \\
\hline $60 \mathrm{C} 10 \mathrm{~L}$ & 439.80 & 439.80 & 5.5 & 0.02 & 439.63 & 439.62 & 0.14 & 96.4 & $0.57 \%$ \\
\hline $60 \mathrm{C} 20 \mathrm{~L}$ & 450.98 & 452.06 & 9.5 & 0.12 & 449.43 & 451.56 & 1.00 & 88.2 & $2.01 \%$ \\
\hline $60 \mathrm{C} 30 \mathrm{~L}$ & 435.20 & 443.31 & 9.3 & 0.36 & 431.42 & 442.76 & 3.08 & 220.1 & $2.44 \%$ \\
\hline $60 \mathrm{C} 40 \mathrm{~L}$ & 434.51 & 462.27 & 19.4 & 0.90 & 436.96 & 462.01 & 8.77 & 77.3 & $2.42 \%$ \\
\hline $60 \mathrm{C} 50 \mathrm{~L}$ & 394.18 & 429.77 & 32.6 & 1.37 & 393.95 & 429.76 & 21.34 & NA & NA \\
\hline $60 \mathrm{C} 60 \mathrm{~L}$ & NA & 496.88 & 42.0 & 3.39 & NA & 496.88 & 52.63 & NA & NA \\
\hline $60 \mathrm{C} 70 \mathrm{~L}$ & NA & 431.65 & 47.0 & 3.38 & NA & 431.33 & 35.11 & NA & NA \\
\hline $60 \mathrm{C} 80 \mathrm{~L}$ & NA & 497.53 & 61.4 & 7.83 & NA & 497.49 & 154.24 & NA & NA \\
\hline 60C90L & NA & 463.64 & 79.4 & 8.33 & NA & 463.58 & 167.61 & NA & NA \\
\hline $60 \mathrm{C} 100 \mathrm{~L}$ & NA & 478.34 & 78.0 & 13.34 & NA & 477.56 & 166.49 & NA & NA \\
\hline 70C10L & 634.87 & 634.87 & 5.5 & 0.03 & 634.78 & 634.78 & 0.21 & 91.2 & $0.20 \%$ \\
\hline $70 \mathrm{C} 20 \mathrm{~L}$ & 620.27 & 623.60 & 5.5 & 0.18 & 619.08 & 623.31 & 1.36 & 112.4 & $0.83 \%$ \\
\hline $70 \mathrm{C} 30 \mathrm{~L}$ & 596.00 & 597.56 & 6.3 & 0.54 & 593.01 & 597.35 & 4.85 & 95.1 & $2.00 \%$ \\
\hline $70 \mathrm{C} 40 \mathrm{~L}$ & 576.72 & 617.43 & 24.8 & 1.44 & 579.99 & 617.03 & 15.56 & NA & NA \\
\hline $70 \mathrm{C} 50 \mathrm{~L}$ & 588.76 & 632.62 & 34.6 & 2.12 & 592.28 & 631.93 & 21.99 & NA & NA \\
\hline $70 \mathrm{C} 60 \mathrm{~L}$ & 598.74 & 631.71 & 30.1 & 3.74 & 599.89 & 631.33 & 38.47 & NA & NA \\
\hline $70 \mathrm{C} 70 \mathrm{~L}$ & NA & 627.74 & 46.3 & 7.46 & NA & 627.02 & 85.88 & NA & NA \\
\hline $70 \mathrm{C} 80 \mathrm{~L}$ & NA & 610.59 & 50.4 & 9.49 & NA & 609.30 & 114.72 & NA & NA \\
\hline 70C90L & NA & 672.02 & 65.7 & 12.43 & NA & 670.83 & 149.19 & NA & NA \\
\hline 70C100L & NA & 629.46 & 87.2 & 17.29 & NA & 628.62 & 218.69 & NA & NA \\
\hline 80C10L & 779.46 & 779.46 & 5.5 & 0.04 & 778.89 & 778.89 & 0.22 & 105.2 & $0.00 \%$ \\
\hline $80 \mathrm{C} 20 \mathrm{~L}$ & 831.00 & 832.98 & 5.8 & 0.26 & 831.00 & 832.98 & 1.90 & 122.2 & $1.17 \%$ \\
\hline $80 \mathrm{C} 30 \mathrm{~L}$ & 800.84 & 800.84 & 6.4 & 0.81 & 800.81 & 800.80 & 6.37 & 136.9 & $2.36 \%$ \\
\hline $80 \mathrm{C} 40 \mathrm{~L}$ & 814.05 & 820.14 & 8.1 & 1.69 & 808.22 & 819.27 & 14.80 & NA & NA \\
\hline $80 \mathrm{C} 50 \mathrm{~L}$ & 800.11 & 825.42 & 12.3 & 2.57 & 812.88 & 824.48 & 29.58 & NA & NA \\
\hline $80 \mathrm{C} 60 \mathrm{~L}$ & NA & 808.67 & 44.8 & 5.74 & NA & 808.23 & 63.36 & NA & NA \\
\hline 80C70L & NA & 864.83 & 43.6 & 9.26 & NA & 863.97 & 106.39 & NA & NA \\
\hline $80 \mathrm{C} 80 \mathrm{~L}$ & NA & 871.79 & 52.1 & 13.45 & NA & 871.22 & 152.16 & NA & NA \\
\hline 80C90L & NA & 809.75 & 68.5 & 16.34 & NA & 808.93 & 194.09 & NA & NA \\
\hline $80 \mathrm{C} 100 \mathrm{~L}$ & NA & 793.55 & 69.6 & 20.08 & NA & 792.90 & 227.53 & NA & NA \\
\hline 90C10L & 1055.9 & 1056.0 & 5.5 & 0.06 & 1055.9 & 1055.9 & 0.36 & 152.6 & $0.16 \%$ \\
\hline $90 \mathrm{C} 20 \mathrm{~L}$ & 1042.8 & 1048.7 & 6.3 & 0.26 & 1042.8 & 1048.7 & 1.71 & 128.8 & $0.62 \%$ \\
\hline $90 \mathrm{C} 30 \mathrm{~L}$ & 1138.3 & 1141.3 & 5.5 & 1.23 & 1138.3 & 1141.3 & 10.76 & NA & NA \\
\hline $90 \mathrm{C} 40 \mathrm{~L}$ & 1042.2 & 1054.7 & 11.6 & 2.32 & 1041.7 & 1054.3 & 22.14 & NA & NA \\
\hline $90 \mathrm{C} 50 \mathrm{~L}$ & 1107.6 & 1117.7 & 8.7 & 4.10 & 1107.6 & 1117.7 & 37.02 & NA & NA \\
\hline $90 \mathrm{C} 60 \mathrm{~L}$ & 1014.9 & 1046.8 & 14.4 & 6.80 & 1020.9 & 1046.0 & 66.91 & NA & NA \\
\hline $90 \mathrm{C} 70 \mathrm{~L}$ & 963.09 & 1001.9 & 25.6 & 8.61 & 953.40 & 1000.3 & 96.99 & NA & NA \\
\hline 90C80L & NA & 1060.9 & 42.9 & 14.72 & NA & 1059.5 & 179.51 & NA & NA \\
\hline 90C90L & NA & 1018.2 & 48.2 & 20.51 & NA & 1017.0 & 236.83 & NA & NA \\
\hline $90 \mathrm{C} 100 \mathrm{~L}$ & NA & 1057.3 & 62.1 & 31.01 & NA & 1056.6 & 422.02 & NA & NA \\
\hline 100C10L & 1320.7 & 1320.7 & 5.5 & 0.08 & 1320.7 & 1319.8 & 0.64 & 117.9 & NA \\
\hline $100 \mathrm{C} 20 \mathrm{~L}$ & 1285.1 & 1287.1 & 5.5 & 0.47 & 1286.2 & 1287.1 & 3.92 & 172.4 & $0.78 \%$ \\
\hline
\end{tabular}




\begin{tabular}{lrrrrrrrrr} 
100C30L & 1227.2 & 1233.1 & 6.3 & 1.06 & 1227.2 & 1233.1 & 7.84 & NA & NA \\
100C40L & 1249.8 & 1252.3 & 5.9 & 2.24 & 1249.2 & 1252.2 & 18.55 & NA & NA \\
100C50L & 1263.7 & 1278.3 & 10.0 & 4.94 & 1265.6 & 1278.1 & 45.02 & NA & NA \\
100C60L & 1263.8 & 1271.8 & 10.4 & 8.40 & 1257.2 & 1271.0 & 84.26 & NA & NA \\
100C70L & NA & 1315.2 & 27.4 & 11.86 & 1277.5 & 1314.6 & 117.34 & NA & NA \\
100C80L & NA & 1231.3 & 27.7 & 16.46 & NA & 1231.3 & 196.48 & NA & NA \\
100C90L & NA & 1296.9 & 45.6 & 23.66 & NA & 1295.1 & 278.57 & NA & NA \\
100 C100L & NA & 1297.6 & 48.0 & 39.80 & NA & 1297.2 & 445.80 & NA & NA \\
\hline
\end{tabular}

Table 4: Results of the metaheuristic with $\mathrm{GRASP}_{a}$ construction phase

\begin{tabular}{|c|c|c|c|c|c|c|c|c|c|}
\hline \multirow[b]{2}{*}{ Instance } & \multicolumn{4}{|c|}{$\operatorname{GRASP}_{a}$} & \multicolumn{3}{|c|}{$\operatorname{GRASP}_{a}+$ Local Search } & \multicolumn{2}{|c|}{ Evaluation } \\
\hline & $\begin{array}{c}\text { exact } \\
\left(\times 10^{7}\right)\end{array}$ & $\begin{array}{c}\text { approx. } \\
\left(\times 10^{7}\right)\end{array}$ & $\bar{d}$ & $\begin{array}{c}\mathrm{CPU} \\
(\mathrm{s})\end{array}$ & $\begin{array}{c}\text { exact } \\
\left(\times 10^{7}\right)\end{array}$ & $\begin{array}{c}\text { approx. } \\
\left(\times 10^{7}\right)\end{array}$ & $\begin{array}{c}\mathrm{CPU} \\
(\mathrm{s})\end{array}$ & speedup & $\begin{array}{c}\text { dev. } \\
\%\end{array}$ \\
\hline 10C10L & 9.6586 & 10.050 & 3.2 & 0.01 & 9.6586 & 10.050 & 0.01 & 24.0 & $1.24 \%$ \\
\hline $10 \mathrm{C} 20 \mathrm{~L}$ & 9.2352 & 9.2400 & 7.3 & 0.01 & 9.0947 & 9.1014 & 0.02 & 44.0 & $0.12 \%$ \\
\hline 10C30L & 9.3541 & 9.6471 & 11.3 & 0.01 & 9.2081 & 9.5157 & 0.05 & 39.8 & $0.45 \%$ \\
\hline 10C40L & 8.9615 & 9.1142 & 15.6 & 0.01 & 8.8257 & 8.9812 & 0.12 & 39.4 & $0.21 \%$ \\
\hline $10 \mathrm{C} 50 \mathrm{~L}$ & 8.5793 & 8.8977 & 18.3 & 0.01 & 8.4107 & 8.7085 & 0.12 & 51.5 & $0.24 \%$ \\
\hline $10 \mathrm{C} 60 \mathrm{~L}$ & 8.8902 & 8.9369 & 6.6 & 0.02 & 7.4931 & 7.6301 & 0.36 & 25.8 & $0.23 \%$ \\
\hline 10C70L & 8.2162 & 8.4402 & 13.7 & 0.03 & 7.6405 & 7.6964 & 0.35 & 43.0 & $0.03 \%$ \\
\hline $10 \mathrm{C} 80 \mathrm{~L}$ & 9.1842 & 9.5825 & 6.9 & 0.06 & 7.9713 & 8.0759 & 1.51 & 16.4 & $0.20 \%$ \\
\hline 10C90L & 9.4706 & 9.4838 & 10.5 & 0.06 & 8.6919 & 8.7251 & 1.49 & 20.3 & $0.15 \%$ \\
\hline 10C100L & 10.012 & 10.120 & 9.8 & 0.09 & 8.4058 & 8.5219 & 2.92 & 14.9 & $0.08 \%$ \\
\hline 20C10L & 51.134 & 51.563 & 3.2 & 0.01 & 50.992 & 51.420 & 0.02 & 54.5 & $0.15 \%$ \\
\hline $20 \mathrm{C} 20 \mathrm{~L}$ & 46.457 & 51.754 & 9.4 & 0.02 & 46.419 & 51.560 & 0.13 & 53.8 & $0.98 \%$ \\
\hline $20 \mathrm{C} 30 \mathrm{~L}$ & 52.105 & 55.661 & 6.3 & 0.03 & 46.473 & 51.573 & 0.34 & 44.0 & $0.25 \%$ \\
\hline $20 \mathrm{C} 40 \mathrm{~L}$ & 43.203 & 47.764 & 9.3 & 0.06 & 40.208 & 44.141 & 0.73 & 46.1 & $0.21 \%$ \\
\hline $20 \mathrm{C} 50 \mathrm{~L}$ & 39.266 & 42.877 & 5.6 & 0.09 & 34.632 & 36.616 & 1.30 & 43.8 & $0.67 \%$ \\
\hline $20 \mathrm{C} 60 \mathrm{~L}$ & 44.770 & 48.570 & 7.3 & 0.12 & 41.325 & 43.751 & 1.86 & 37.3 & $0.37 \%$ \\
\hline $20 \mathrm{C} 70 \mathrm{~L}$ & 36.415 & 39.313 & 15.5 & 0.18 & 33.707 & 35.992 & 2.16 & 38.7 & $0.44 \%$ \\
\hline $20 \mathrm{C} 80 \mathrm{~L}$ & 39.612 & 43.583 & 10.2 & 0.30 & 36.143 & 37.831 & 5.71 & 43.5 & $0.33 \%$ \\
\hline 20C90L & 34.935 & 38.740 & 20.2 & 0.35 & 32.757 & 34.727 & 5.49 & 54.5 & $0.40 \%$ \\
\hline 20C100L & 44.278 & 48.547 & 9.8 & 0.49 & 38.685 & 40.193 & 12.14 & 32.1 & $0.45 \%$ \\
\hline $30 \mathrm{C} 10 \mathrm{~L}$ & 111.66 & 117.72 & 4.6 & 0.01 & 113.38 & 117.68 & 0.04 & 69.0 & $1.54 \%$ \\
\hline $30 \mathrm{C} 20 \mathrm{~L}$ & 104.40 & 113.51 & 8.1 & 0.03 & 105.95 & 113.23 & 0.22 & 52.9 & $1.72 \%$ \\
\hline $30 \mathrm{C} 30 \mathrm{~L}$ & 103.68 & 117.03 & 10.9 & 0.12 & 104.43 & 116.83 & 1.01 & 45.2 & $1.08 \%$ \\
\hline $30 \mathrm{C} 40 \mathrm{~L}$ & 81.843 & 91.313 & 15.1 & 0.14 & 80.941 & 90.238 & 1.12 & 62.2 & $0.59 \%$ \\
\hline $30 \mathrm{C} 50 \mathrm{~L}$ & 91.019 & 105.48 & 18.4 & 0.30 & 90.055 & 104.08 & 2.88 & 51.0 & $0.37 \%$ \\
\hline $30 \mathrm{C} 60 \mathrm{~L}$ & 91.431 & 103.24 & 21.5 & 0.37 & 89.115 & 101.11 & 3.75 & 55.8 & $0.67 \%$ \\
\hline 30C70L & 95.706 & 113.53 & 24.4 & 0.94 & 91.298 & 105.42 & 10.79 & 49.6 & $0.87 \%$ \\
\hline $30 \mathrm{C} 80 \mathrm{~L}$ & 77.608 & 88.557 & 28.6 & 0.69 & 75.539 & 85.396 & 7.19 & 61.3 & $0.55 \%$ \\
\hline 30C90L & 88.128 & 102.09 & 31.0 & 1.18 & 86.134 & 97.830 & 13.87 & NA & NA \\
\hline $30 \mathrm{C} 100 \mathrm{~L}$ & 92.065 & 105.81 & 24.7 & 1.97 & 88.110 & 98.423 & 26.65 & NA & NA \\
\hline $40 \mathrm{C} 10 \mathrm{~L}$ & 212.93 & 212.93 & 2.9 & 0.01 & 208.81 & 211.73 & 0.08 & 110.1 & $1.01 \%$ \\
\hline $40 \mathrm{C} 20 \mathrm{~L}$ & 204.94 & 219.75 & 5.0 & 0.06 & 205.42 & 219.49 & 0.55 & 102.3 & $0.99 \%$ \\
\hline 40C30L & 206.96 & 226.95 & 11.2 & 0.21 & 208.17 & 224.33 & 1.86 & 62.8 & $1.34 \%$ \\
\hline 40C40L & 171.45 & 193.34 & 15.1 & 0.32 & 172.81 & 193.11 & 2.65 & 70.9 & $1.03 \%$ \\
\hline $40 \mathrm{C50L}$ & 182.68 & 212.39 & 19.4 & 0.82 & 183.35 & 211.20 & 7.83 & 45.9 & $0.78 \%$ \\
\hline $40 \mathrm{C} 60 \mathrm{~L}$ & 171.78 & 196.18 & 22.5 & 1.06 & 171.46 & 195.97 & 9.59 & 65.6 & $0.30 \%$ \\
\hline 40C70L & NA & 210.61 & 26.6 & 2.27 & 177.34 & 210.23 & 22.24 & NA & NA \\
\hline $40 \mathrm{C} 80 \mathrm{~L}$ & NA & 197.65 & 30.8 & 3.24 & NA & 197.48 & 28.98 & NA & NA \\
\hline 40C90L & NA & 177.49 & 33.2 & 3.32 & NA & 175.80 & 37.20 & NA & NA \\
\hline 40C100L & NA & 177.13 & 37.4 & 3.57 & NA & 175.82 & 42.00 & NA & NA \\
\hline $50 \mathrm{C} 10 \mathrm{~L}$ & 340.46 & 340.46 & 2.9 & 0.02 & 335.03 & 339.50 & 0.15 & 59.2 & $0.23 \%$ \\
\hline $50 \mathrm{C} 20 \mathrm{~L}$ & 314.81 & 316.05 & 5.9 & 0.10 & 308.25 & 315.04 & 0.82 & 56.0 & $2.56 \%$ \\
\hline $50 \mathrm{C} 30 \mathrm{~L}$ & 288.47 & 309.20 & 9.9 & 0.24 & 290.58 & 308.15 & 1.79 & 74.9 & $1.68 \%$ \\
\hline $50 \mathrm{C} 40 \mathrm{~L}$ & 286.97 & 320.22 & 15.1 & 0.57 & 290.70 & 319.25 & 4.89 & 65.2 & $1.30 \%$ \\
\hline 50C50L & 267.80 & 287.06 & 16.6 & 0.71 & 264.34 & 283.66 & 6.13 & 78.5 & $0.71 \%$ \\
\hline $50 \mathrm{C60L}$ & NA & 292.21 & 22.6 & 1.54 & 253.88 & 290.65 & 14.26 & NA & NA \\
\hline $50 \mathrm{C} 70 \mathrm{~L}$ & NA & 306.54 & 26.6 & 3.25 & NA & 306.10 & 35.45 & NA & NA \\
\hline
\end{tabular}




\begin{tabular}{|c|c|c|c|c|c|c|c|c|c|}
\hline $50 \mathrm{C} 80 \mathrm{~L}$ & NA & 301.09 & 31.0 & 4.25 & NA & 300.16 & 46.64 & NA & NA \\
\hline 50C90L & NA & 296.18 & 34.8 & 4.95 & NA & 295.43 & 51.45 & NA & NA \\
\hline 50C100L & NA & 271.46 & 38.9 & 5.55 & NA & 270.42 & 56.17 & NA & NA \\
\hline $60 \mathrm{C} 10 \mathrm{~L}$ & 439.63 & 439.80 & 0.0 & 0.02 & 439.63 & 439.63 & 0.22 & 61.3 & $0.57 \%$ \\
\hline $60 \mathrm{C} 20 \mathrm{~L}$ & 452.69 & 452.69 & 5.9 & 0.12 & 450.99 & 452.06 & 0.93 & 94.8 & $2.36 \%$ \\
\hline 60C30L & 444.62 & 444.62 & 8.0 & 0.36 & 432.88 & 442.70 & 3.33 & 203.6 & $2.79 \%$ \\
\hline $60 \mathrm{C} 40 \mathrm{~L}$ & 457.66 & 464.79 & 11.4 & 0.90 & 444.35 & 461.97 & 8.37 & 81.0 & $4.15 \%$ \\
\hline $60 \mathrm{C50L}$ & NA & 431.83 & 18.5 & 1.38 & NA & 431.83 & 11.75 & NA & NA \\
\hline $60 \mathrm{C} 60 \mathrm{~L}$ & NA & 499.61 & 23.4 & 3.41 & 450.71 & 496.28 & 30.74 & NA & NA \\
\hline $60 \mathrm{C} 70 \mathrm{~L}$ & NA & 434.60 & 26.5 & 3.39 & NA & 431.56 & 31.38 & NA & NA \\
\hline $60 \mathrm{C} 80 \mathrm{~L}$ & NA & 499.27 & 31.0 & 7.83 & NA & 497.45 & 74.99 & NA & NA \\
\hline 60C90L & NA & 464.19 & 34.7 & 8.38 & NA & 462.91 & 80.61 & NA & NA \\
\hline $60 \mathrm{C} 100 \mathrm{~L}$ & NA & 479.86 & 39.1 & 13.37 & NA & 477.79 & 135.67 & NA & NA \\
\hline 70C10L & 637.06 & 637.06 & 0.3 & 0.03 & 634.78 & 634.78 & 0.22 & 87.0 & $0.20 \%$ \\
\hline $70 \mathrm{C} 20 \mathrm{~L}$ & 624.15 & 624.15 & 5.9 & 0.18 & 619.08 & 623.31 & 1.19 & 128.4 & $0.83 \%$ \\
\hline $70 \mathrm{C} 30 \mathrm{~L}$ & 598.32 & 598.32 & 7.8 & 0.55 & 593.02 & 597.35 & 4.20 & 109.8 & $2.00 \%$ \\
\hline $70 C 40 \mathrm{~L}$ & 575.22 & 619.63 & 15.1 & 1.44 & 588.52 & 617.19 & 12.35 & NA & NA \\
\hline $70 \mathrm{C50L}$ & NA & 636.00 & 18.4 & 2.14 & 593.26 & 632.14 & 18.23 & NA & NA \\
\hline $70 \mathrm{C60L}$ & NA & 636.22 & 22.5 & 3.78 & 597.07 & 631.65 & 32.86 & NA & NA \\
\hline $70 \mathrm{C} 70 \mathrm{~L}$ & NA & 631.72 & 26.6 & 7.46 & NA & 626.94 & 70.60 & NA & NA \\
\hline $70 \mathrm{C} 80 \mathrm{~L}$ & NA & 613.46 & 30.7 & 9.55 & NA & 609.46 & 91.49 & NA & NA \\
\hline 70C90L & NA & 674.67 & 33.9 & 12.43 & NA & 670.88 & 140.78 & NA & NA \\
\hline 70C100L & NA & 631.03 & 39.1 & 17.32 & NA & 628.55 & 206.99 & NA & NA \\
\hline 80C10L & 780.90 & 780.90 & 2.9 & 0.04 & 778.89 & 778.89 & 0.29 & 79.8 & $0.00 \%$ \\
\hline $80 \mathrm{C} 20 \mathrm{~L}$ & 833.22 & 833.22 & 5.9 & 0.27 & 830.62 & 833.03 & 1.84 & 126.2 & $1.12 \%$ \\
\hline 80C30L & 801.48 & 801.48 & 8.0 & 0.82 & 800.81 & 800.81 & 6.66 & 131.0 & $2.36 \%$ \\
\hline $80 \mathrm{C} 40 \mathrm{~L}$ & 821.55 & 821.55 & 10.9 & 1.70 & 812.02 & 820.00 & 14.56 & NA & NA \\
\hline 80C50L & 826.13 & 826.13 & 12.8 & 2.59 & 813.63 & 824.57 & 23.00 & NA & NA \\
\hline $80 \mathrm{C60L}$ & NA & 813.53 & 23.5 & 5.78 & NA & 808.19 & 58.85 & NA & NA \\
\hline 80C70L & 834.98 & 869.28 & 20.6 & 9.33 & NA & 864.33 & 91.60 & NA & NA \\
\hline 80C80L & NA & 878.16 & 31.0 & 13.50 & NA & 871.08 & 145.33 & NA & NA \\
\hline 80C90L & NA & 813.41 & 34.6 & 16.46 & NA & 809.41 & 164.89 & NA & NA \\
\hline 80C100L & NA & 800.85 & 38.9 & 20.21 & NA & 793.22 & 193.30 & NA & NA \\
\hline 90C10L & 1056.8 & 1056.8 & 2.9 & 0.06 & 1056.0 & 1056.0 & 0.49 & 112.1 & $0.16 \%$ \\
\hline $90 \mathrm{C} 20 \mathrm{~L}$ & 1049.6 & 1049.5 & 5.9 & 0.27 & 1046.2 & 1048.8 & 1.64 & 134.3 & $0.94 \%$ \\
\hline $90 \mathrm{C} 30 \mathrm{~L}$ & 1142.4 & 1142.4 & 8.0 & 1.23 & 1139.4 & 1141.5 & 9.78 & NA & NA \\
\hline $90 \mathrm{C} 40 \mathrm{~L}$ & 1056.6 & 1056.6 & 10.9 & 2.34 & 1041.7 & 1054.4 & 21.33 & NA & NA \\
\hline 90C50L & 1119.3 & 1119.3 & 12.8 & 4.13 & 1119.0 & 1119.0 & 46.49 & NA & NA \\
\hline $90 \mathrm{C} 60 \mathrm{~L}$ & 1048.9 & 1048.9 & 15.8 & 6.82 & 1048.9 & 1048.9 & 79.17 & NA & NA \\
\hline $90 \mathrm{C} 70 \mathrm{~L}$ & 1006.6 & 1006.6 & 18.1 & 8.64 & 955.61 & 1000.3 & 96.17 & NA & NA \\
\hline $90 \mathrm{C} 80 \mathrm{~L}$ & NA & 1069.5 & 27.6 & 14.81 & NA & 1060.5 & 138.21 & NA & NA \\
\hline 90C90L & NA & 1025.3 & 29.7 & 20.54 & NA & 1017.1 & 200.46 & NA & NA \\
\hline 90C100L & NA & 1063.2 & 37.9 & 31.21 & NA & 1056.5 & 311.32 & NA & NA \\
\hline 100C10L & 1322.8 & 1322.8 & 2.9 & 0.08 & 1319.9 & 1319.9 & 0.69 & 109.3 & $0.00 \%$ \\
\hline 100C20L & 1287.3 & 1287.3 & 5.9 & 0.47 & 1286.2 & 1287.2 & 3.24 & 208.5 & $0.78 \%$ \\
\hline 100C30L & 1234.5 & 1234.5 & 7.8 & 1.07 & 1230.9 & 1233.2 & 7.89 & NA & NA \\
\hline 100C40L & 1253.5 & 1253.5 & 10.9 & 2.25 & 1250.8 & 1252.3 & 17.16 & NA & NA \\
\hline $100 \mathrm{C} 50 \mathrm{~L}$ & 1280.4 & 1280.4 & 12.8 & 4.95 & 1270.8 & 1278.3 & 47.81 & NA & NA \\
\hline $100 \mathrm{C} 60 \mathrm{~L}$ & 1273.2 & 1273.2 & 15.8 & 8.49 & 1255.4 & 1271.5 & 88.46 & NA & NA \\
\hline 100C70L & 1318.0 & 1319.8 & 18.1 & 11.94 & 1282.3 & 1315.4 & 110.78 & NA & NA \\
\hline 100C80L & 1233.5 & 1236.7 & 21.3 & 16.59 & NA & 1231.4 & 153.78 & NA & NA \\
\hline 100C90L & NA & 1306.7 & 31.6 & 23.80 & NA & 1295.9 & 231.56 & NA & NA \\
\hline 100C100L & 1298.4 & 1308.0 & 26.9 & 40.04 & NA & 1296.6 & 436.56 & NA & NA \\
\hline
\end{tabular}

Table 5: Results of the metaheuristic with $\mathrm{GRASP}_{b}$ construction phase

\begin{tabular}{|c|c|c|c|c|c|c|c|c|c|}
\hline \multirow[b]{2}{*}{ Instance } & \multicolumn{4}{|c|}{$\operatorname{GRASP}_{b}$} & \multicolumn{3}{|c|}{ GRASP $_{b}+$ Local Search } & \multicolumn{2}{|c|}{ Evaluation } \\
\hline & $\begin{array}{l}\text { exact } \\
\left(\times 10^{7}\right)\end{array}$ & $\begin{array}{l}\text { approx. } \\
\left(\times 10^{7}\right)\end{array}$ & $\bar{d}$ & $\begin{array}{l}\mathrm{CPU} \\
(\mathrm{s})\end{array}$ & $\begin{array}{l}\text { exact } \\
\left(\times 10^{7}\right)\end{array}$ & $\begin{array}{l}\text { approx. } \\
\left(\times 10^{7}\right)\end{array}$ & $\begin{array}{c}\mathrm{CPU} \\
(\mathrm{s})\end{array}$ & speedup & $\begin{array}{c}\text { dev. } \\
\%\end{array}$ \\
\hline $10 \mathrm{C} 10 \mathrm{~L}$ & 9.659 & 10.050 & 3.2 & 0.01 & 9.659 & 10.050 & 0.01 & 24.0 & $1.24 \%$ \\
\hline $10 \mathrm{C} 20 \mathrm{~L}$ & 9.233 & 9.238 & 7.3 & 0.06 & 9.095 & 9.101 & 0.07 & 12.6 & $0.12 \%$ \\
\hline
\end{tabular}




\begin{tabular}{|c|c|c|c|c|c|c|c|c|c|}
\hline 10C30L & 9.354 & 9.647 & 11.3 & 0.08 & 9.208 & 9.516 & 0.12 & 16.6 & $0.45 \%$ \\
\hline $10 \mathrm{C} 40 \mathrm{~L}$ & 8.921 & 9.074 & 14.4 & 0.20 & 8.821 & 8.977 & 0.31 & 15.3 & $0.15 \%$ \\
\hline $10 \mathrm{C} 50 \mathrm{~L}$ & 8.531 & 8.850 & 17.4 & 0.40 & 8.411 & 8.708 & 0.51 & 12.1 & $0.24 \%$ \\
\hline $10 \mathrm{C} 60 \mathrm{~L}$ & 7.627 & 7.809 & 22.4 & 0.76 & 7.493 & 7.630 & 1.00 & 9.3 & $0.23 \%$ \\
\hline 10C70L & 7.744 & 7.793 & 32.8 & 1.41 & 7.641 & 7.692 & 1.58 & 9.5 & $0.04 \%$ \\
\hline $10 \mathrm{C} 80 \mathrm{~L}$ & 8.165 & 8.268 & 30.7 & 1.44 & 7.971 & 8.076 & 2.56 & 9.7 & $0.20 \%$ \\
\hline 10C90L & 8.904 & 8.928 & 33.2 & 1.15 & 8.889 & 8.922 & 2.24 & 13.5 & $2.42 \%$ \\
\hline 10C100L & 8.612 & 8.725 & 35.7 & 1.72 & 8.409 & 8.523 & 3.86 & 11.2 & $0.12 \%$ \\
\hline 20C10L & 51.134 & 51.563 & 3.2 & 0.01 & 50.992 & 51.420 & 0.02 & 54.5 & $0.15 \%$ \\
\hline $20 \mathrm{C} 20 \mathrm{~L}$ & 46.457 & 51.754 & 9.4 & 0.15 & 46.419 & 51.560 & 0.26 & 26.9 & $0.98 \%$ \\
\hline $20 \mathrm{C} 30 \mathrm{~L}$ & 46.645 & 51.733 & 11.2 & 0.58 & 46.473 & 51.573 & 0.88 & 17.0 & $0.25 \%$ \\
\hline 20C40L & 40.447 & 44.397 & 15.5 & 0.99 & 40.208 & 44.141 & 1.59 & 21.2 & $0.21 \%$ \\
\hline $20 \mathrm{C} 50 \mathrm{~L}$ & 34.964 & 36.916 & 18.7 & 1.21 & 34.632 & 36.616 & 2.25 & 25.3 & $0.67 \%$ \\
\hline $20 \mathrm{C} 60 \mathrm{~L}$ & 41.728 & 44.121 & 22.5 & 2.62 & 41.335 & 43.757 & 4.09 & 17.0 & $0.39 \%$ \\
\hline $20 \mathrm{C} 70 \mathrm{~L}$ & 34.133 & 36.407 & 25.5 & 5.64 & 33.707 & 35.992 & 7.40 & 11.3 & $0.44 \%$ \\
\hline 20C80L & 36.691 & 38.406 & 29.2 & 3.60 & 36.300 & 38.328 & 8.06 & 30.8 & $0.77 \%$ \\
\hline 20C90L & 33.382 & 35.324 & 33.6 & 6.34 & 32.757 & 34.727 & 10.95 & 27.3 & $0.40 \%$ \\
\hline 20C100L & 39.150 & 40.805 & 36.8 & 12.29 & 38.685 & 40.193 & 21.48 & 18.2 & $0.45 \%$ \\
\hline 30C10L & 113.38 & 117.68 & 2.7 & 0.04 & 113.38 & 117.68 & 0.07 & 39.4 & $1.54 \%$ \\
\hline $30 \mathrm{C} 20 \mathrm{~L}$ & 104.21 & 113.31 & 7.4 & 0.28 & 105.95 & 113.23 & 0.48 & 24.2 & $1.72 \%$ \\
\hline $30 \mathrm{C} 30 \mathrm{~L}$ & 103.36 & 117.00 & 11.2 & 2.04 & 103.66 & 116.76 & 2.94 & 15.5 & $0.34 \%$ \\
\hline $30 \mathrm{C} 40 \mathrm{~L}$ & 81.612 & 90.993 & 15.2 & 1.93 & 80.733 & 90.109 & 2.92 & 23.9 & $0.33 \%$ \\
\hline $30 \mathrm{C} 50 \mathrm{~L}$ & 90.350 & 104.33 & 18.7 & 3.77 & 90.227 & 104.03 & 6.45 & 22.8 & $0.56 \%$ \\
\hline $30 \mathrm{C} 60 \mathrm{~L}$ & 89.684 & 101.47 & 22.7 & 6.28 & 89.268 & 101.02 & 9.54 & 22.0 & $0.84 \%$ \\
\hline $30 \mathrm{C} 70 \mathrm{~L}$ & 91.632 & 105.71 & 26.7 & 15.72 & 91.205 & 105.40 & 25.51 & 21.0 & $0.77 \%$ \\
\hline $30 \mathrm{C} 80 \mathrm{~L}$ & 76.525 & 86.310 & 31.0 & 16.39 & 75.539 & 85.396 & 22.84 & 19.3 & $0.55 \%$ \\
\hline 30C90L & NA & 98.572 & 34.8 & 19.90 & 86.134 & 97.830 & 32.65 & NA & NA \\
\hline $30 \mathrm{C} 100 \mathrm{~L}$ & NA & 98.901 & 37.9 & 50.94 & 88.075 & 98.383 & 74.12 & NA & NA \\
\hline 40C10L & 207.83 & 212.24 & 3.8 & 0.15 & 208.81 & 211.73 & 0.22 & 40.1 & $1.01 \%$ \\
\hline $40 \mathrm{C} 20 \mathrm{~L}$ & 205.08 & 219.49 & 7.1 & 0.90 & 204.85 & 219.47 & 1.36 & 41.4 & $0.71 \%$ \\
\hline 40C30L & 210.73 & 225.72 & 12.7 & 3.36 & 209.90 & 224.18 & 5.14 & 22.7 & $2.18 \%$ \\
\hline 40C40L & 171.86 & 193.29 & 15.0 & 3.34 & 173.22 & 192.98 & 6.04 & 31.1 & $1.27 \%$ \\
\hline $40 \mathrm{C} 50 \mathrm{~L}$ & 183.22 & 212.14 & 19.2 & 11.20 & 183.41 & 211.20 & 18.34 & 19.6 & $0.81 \%$ \\
\hline $40 \mathrm{C} 60 \mathrm{~L}$ & 171.78 & 196.18 & 22.5 & 10.68 & 171.46 & 195.97 & 19.49 & 32.3 & $0.30 \%$ \\
\hline 40C70L & NA & 210.55 & 26.5 & 38.34 & 177.34 & 210.23 & 58.43 & NA & NA \\
\hline $40 \mathrm{C} 80 \mathrm{~L}$ & NA & 197.63 & 30.2 & 56.79 & NA & 197.51 & 83.58 & NA & NA \\
\hline 40C90L & NA & 176.11 & 33.8 & 74.47 & NA & 175.79 & 107.53 & NA & NA \\
\hline 40C100L & NA & 176.57 & 37.7 & 39.89 & NA & 175.84 & 76.83 & NA & NA \\
\hline $50 \mathrm{C} 10 \mathrm{~L}$ & 335.03 & 339.50 & 3.5 & 0.39 & 335.03 & 339.50 & 0.51 & 17.4 & $0.23 \%$ \\
\hline $50 \mathrm{C} 20 \mathrm{~L}$ & 310.49 & 315.57 & 6.8 & 0.92 & 307.00 & 314.54 & 1.70 & 27.0 & $2.14 \%$ \\
\hline $50 \mathrm{C} 30 \mathrm{~L}$ & 287.41 & 308.97 & 10.8 & 2.15 & 290.58 & 308.15 & 3.68 & 36.4 & $1.68 \%$ \\
\hline $50 \mathrm{C} 40 \mathrm{~L}$ & 288.08 & 320.03 & 15.3 & 6.82 & 289.05 & 319.52 & 10.96 & 29.1 & $0.73 \%$ \\
\hline $50 \mathrm{C} 50 \mathrm{~L}$ & 268.60 & 285.89 & 22.3 & 9.78 & 268.21 & 283.42 & 15.16 & 31.8 & $2.19 \%$ \\
\hline $50 \mathrm{C} 60 \mathrm{~L}$ & NA & 291.74 & 22.4 & 31.05 & 253.84 & 290.68 & 43.05 & NA & NA \\
\hline $50 \mathrm{C} 70 \mathrm{~L}$ & NA & 306.54 & 26.6 & 34.01 & NA & 306.10 & 67.52 & NA & NA \\
\hline $50 \mathrm{C} 80 \mathrm{~L}$ & NA & 300.90 & 30.9 & 115.59 & NA & 300.07 & 153.42 & NA & NA \\
\hline $50 \mathrm{C} 90 \mathrm{~L}$ & NA & 295.96 & 34.9 & 73.84 & NA & 295.43 & 121.34 & NA & NA \\
\hline 50C100L & NA & 271.46 & 38.9 & 59.32 & NA & 270.42 & 111.42 & NA & NA \\
\hline $60 \mathrm{C} 10 \mathrm{~L}$ & 439.80 & 439.80 & 2.9 & 0.22 & 439.63 & 439.63 & 0.33 & 40.9 & $0.57 \%$ \\
\hline $60 \mathrm{C} 20 \mathrm{~L}$ & 452.43 & 452.43 & 5.9 & 1.14 & 450.99 & 452.06 & 1.89 & 46.7 & $2.36 \%$ \\
\hline $60 \mathrm{C} 30 \mathrm{~L}$ & 440.83 & 443.68 & 7.8 & 4.88 & 434.62 & 443.38 & 7.46 & 90.9 & $3.20 \%$ \\
\hline $60 \mathrm{C} 40 \mathrm{~L}$ & 441.97 & 464.68 & 16.6 & 13.39 & 442.05 & 462.39 & 20.61 & 32.9 & $3.61 \%$ \\
\hline $60 \mathrm{C} 50 \mathrm{~L}$ & 392.51 & 431.21 & 18.0 & 15.03 & 395.99 & 429.33 & 25.95 & NA & NA \\
\hline $60 \mathrm{C} 60 \mathrm{~L}$ & NA & 499.11 & 22.9 & 46.35 & 450.06 & 496.60 & 76.83 & NA & NA \\
\hline $60 \mathrm{C} 70 \mathrm{~L}$ & NA & 434.60 & 26.5 & 33.46 & NA & 431.56 & 61.95 & NA & NA \\
\hline $60 \mathrm{C} 80 \mathrm{~L}$ & NA & 499.14 & 30.9 & 82.56 & NA & 497.36 & 154.30 & NA & NA \\
\hline $60 \mathrm{C} 90 \mathrm{~L}$ & NA & 464.07 & 34.1 & 212.92 & NA & 462.89 & 292.82 & NA & NA \\
\hline 60C100L & NA & 479.79 & 38.9 & 199.49 & NA & 477.76 & 323.37 & NA & NA \\
\hline $70 \mathrm{C} 10 \mathrm{~L}$ & 634.88 & 634.88 & 2.9 & 0.34 & 634.78 & 634.78 & 0.49 & 39.1 & $0.20 \%$ \\
\hline $70 \mathrm{C} 20 \mathrm{~L}$ & 623.83 & 623.83 & 5.9 & 1.52 & 619.08 & 623.31 & 2.52 & 60.6 & $0.83 \%$ \\
\hline $70 \mathrm{C} 30 \mathrm{~L}$ & 595.34 & 597.43 & 8.0 & 9.57 & 593.02 & 597.35 & 13.22 & 34.9 & $2.00 \%$ \\
\hline $70 \mathrm{C} 40 \mathrm{~L}$ & 579.83 & 618.45 & 14.3 & 16.48 & 581.75 & 617.10 & 28.01 & NA & NA \\
\hline $70 \mathrm{C50L}$ & NA & 634.66 & 19.4 & 31.00 & 594.83 & 632.23 & 48.66 & NA & NA \\
\hline $70 \mathrm{C} 60 \mathrm{~L}$ & NA & 634.98 & 26.8 & 98.87 & 598.63 & 631.44 & 134.74 & NA & NA \\
\hline 70C70L & NA & 630.24 & 25.6 & 144.88 & NA & 626.86 & 210.60 & NA & NA \\
\hline
\end{tabular}




\begin{tabular}{|c|c|c|c|c|c|c|c|c|c|}
\hline 70C80L & NA & 613.12 & 30.5 & 162.22 & NA & 609.55 & 241.58 & NA & NA \\
\hline 70C90L & NA & 674.29 & 33.7 & 158.78 & NA & 670.91 & 269.16 & NA & NA \\
\hline 70C100L & NA & 630.81 & 38.9 & 503.42 & NA & 628.51 & 661.66 & NA & NA \\
\hline 80C10L & 779.46 & 779.46 & 2.9 & 0.33 & 778.89 & 778.89 & 0.57 & 40.6 & $0.00 \%$ \\
\hline $80 \mathrm{C} 20 \mathrm{~L}$ & 833.07 & 833.07 & 5.9 & 4.08 & 831.00 & 832.98 & 5.66 & 41.0 & $1.17 \%$ \\
\hline 80C30L & 800.85 & 800.85 & 7.8 & 10.84 & 800.81 & 800.81 & 15.78 & 55.3 & $2.36 \%$ \\
\hline $80 \mathrm{C} 40 \mathrm{~L}$ & 817.40 & 820.80 & 11.1 & 21.51 & 813.52 & 819.92 & 33.65 & NA & NA \\
\hline 80C50L & 821.12 & 825.37 & 13.5 & 27.66 & 819.75 & 825.06 & 46.73 & NA & NA \\
\hline $80 \mathrm{C60L}$ & NA & 812.86 & 22.7 & 84.74 & NA & 808.37 & 139.69 & NA & NA \\
\hline 80C70L & 834.98 & 869.28 & 20.6 & 92.93 & NA & 864.33 & 177.57 & NA & NA \\
\hline 80C80L & NA & 877.29 & 29.7 & 171.16 & NA & 871.46 & 282.15 & NA & NA \\
\hline 80C90L & NA & 813.05 & 34.1 & 274.50 & NA & 809.36 & 426.58 & NA & NA \\
\hline 80C100L & NA & 799.76 & 38.9 & 429.57 & NA & 793.42 & 606.42 & NA & NA \\
\hline 90C10L & 1056.0 & 1056.0 & 2.9 & 0.53 & 1056.0 & 1056.0 & 0.93 & 59.1 & $0.16 \%$ \\
\hline $90 \mathrm{C} 20 \mathrm{~L}$ & 1049.6 & 1049.5 & 5.9 & 1.85 & 1046.2 & 1048.8 & 3.22 & 68.4 & $0.94 \%$ \\
\hline 90C30L & 1140.0 & 1141.4 & 7.9 & 17.10 & 1139.0 & 1141.4 & 25.65 & NA & NA \\
\hline $90 \mathrm{C} 40 \mathrm{~L}$ & 1052.6 & 1056.2 & 11.1 & 54.30 & 1041.7 & 1054.4 & 74.60 & NA & NA \\
\hline $90 \mathrm{C50L}$ & 1116.1 & 1118.9 & 12.7 & 79.66 & 1105.6 & 1117.6 & 117.13 & NA & NA \\
\hline $90 \mathrm{C60L}$ & 1048.9 & 1048.9 & 15.8 & 66.41 & 1048.9 & 1048.9 & 140.84 & NA & NA \\
\hline $90 \mathrm{C} 70 \mathrm{~L}$ & 987.14 & 1005.6 & 20.1 & 143.66 & NA & 1000.4 & 220.10 & NA & NA \\
\hline $90 \mathrm{C} 80 \mathrm{~L}$ & NA & 1067.4 & 36.1 & 259.89 & NA & 1060.0 & 394.19 & NA & NA \\
\hline 90C90L & 1021.9 & 1025.0 & 23.2 & 384.88 & NA & 1017.1 & 603.45 & NA & NA \\
\hline 90C100L & NA & 1061.6 & 37.6 & 343.05 & NA & 1056.7 & 628.07 & NA & NA \\
\hline 100C10L & 1320.7 & 1320.7 & 2.9 & 0.82 & 1319.9 & 1319.9 & 1.42 & 53.1 & $0.00 \%$ \\
\hline 100C20L & 1287.3 & 1287.3 & 5.9 & 3.56 & 1286.2 & 1287.2 & 6.36 & 106.2 & $0.78 \%$ \\
\hline 100C30L & 1233.7 & 1233.7 & 7.9 & 19.98 & 1230.9 & 1233.2 & 26.77 & NA & NA \\
\hline 100C40L & 1252.9 & 1252.9 & 10.9 & 28.55 & 1249.2 & 1252.3 & 43.74 & NA & NA \\
\hline 100C50L & 1274.7 & 1279.2 & 12.7 & 96.21 & 1265.7 & 1278.2 & 136.24 & NA & NA \\
\hline 100C60L & 1272.9 & 1272.9 & 15.8 & 147.70 & 1268.6 & 1271.9 & 218.19 & NA & NA \\
\hline 100C70L & 1315.4 & 1319.7 & 18.5 & 153.73 & 1294.6 & 1315.5 & 246.88 & NA & NA \\
\hline $100 \mathrm{C} 80 \mathrm{~L}$ & 1230.7 & 1236.6 & 21.5 & 209.44 & 1196.5 & 1231.5 & 356.20 & NA & NA \\
\hline 100C90L & NA & 1304.5 & 40.0 & 294.54 & NA & 1295.9 & 510.34 & NA & NA \\
\hline $100 \mathrm{C} 100 \mathrm{~L}$ & NA & 1306.6 & 47.8 & 721.55 & NA & 1296.9 & 1114.17 & NA & NA \\
\hline
\end{tabular}

600

\section{References}

S. Alumur and B.Y. Kara. Network hub location problems: The state of the art. European Journal of Operational Research, 190(1):1-21, 2008.

P. Arnold, D. Peeters, I. Thomas, and H. Marchand. Pour une localisation optimale des centre de transbordement intermodaux entre réseaux de transport: formulation et extensions. The Canadian Geographer, 45(3):427-436, 2001.

N. Boland, M. Krishnamoorthy, A.T. Ernst, and J. Ebery. Preprocessing and cutting for multiple allocation hub location problems. European Journal of Operational Research, 155(3):638-653, 2004.

Y.M. Bontekoning, C. Macharis, and J.J. Trip. Is a new applied transportation research field ${ }_{610}$ emerging? - a review of intermodal rail-truck freight transport literature. Transportation Research Part A: Policy and Practice, 38(1):1-34, 2004.

C.T. Bornstein and H.B. Azlan. The use of reduction tests and simulated annealing for the capacitated plant location problem. Location Science, 6:67-81, 1998.

G. Bühler and P. Jochem. $\mathrm{CO}_{2}$ emission reduction in freight transports how to stimulate 615 environmental friendly behaviour? ZEW Discussion Papers 08-066, ZEW - Zentrum für 
Europäische Wirtschaftsforschung / Center for European Economic Research, 2008. URL http://ideas.repec.org/p/zbw/zewdip/7389.html.

J.F. Campbell. Integer programming formulations of discrete hub location problems. European Journal of Operational Research, 72(2):387-405, 1994.

T.G. Crainic, A. Frangioni, and B. Gendron. Bundle-based relaxation methods for multicommodity capacitated fixed charge network design. Discrete Applied Mathematics, 112 (1-3):73-99, 2001.

U. Derigs and R. Kaiser. Applying the attribute based hill climber heuristic to the vehicle routing problem. European Journal of Operations Research, 177:719-732, 2007.

J. Ebery, M. Krishnamoorthy, A. Ernst, and N. Boland. The capacitated multiple allocation hub location problem: Formulations and algorithms. European Journal of Operational Research, 120(3):614-631, 2000.

L. Ferreira and J. Sigut. Measuring the performance of intermodal freight terminals. Transportation Planning and Technology, 17(3), 1993.

V.J.M.F. Filho and R.D. Galvão. A tabu search heuristic for the concentrator location problem. Location Science, 6(1):189-209, 1998.

A. Frangioni and B. Gendron. 0-1 reformulations of the multicommodity capacitated network design problem. Discrete Applied Mathematics, 157(6):1229-1241, 2009.

B. Groothedde and L.A. Tavasszy. Optimalisatie van terminallocaties in een multimodaal netwerk met simulated annealing. In Proceedings van de Vervoerslogistieke Werkdagen 1999, 1999.

M. Janic. Modelling the full cost of an intermodal and road freight transport network. Transportation Research. Part D, Transport and Environment, 12(1):33-44, 2007.

J.H. Jaramillo, J. Bhadury, and R. Batta. On the use of genetic algorithms to solve location problems. Computers and Operations Research, 29(6):761-779, 2002.

C. Macharis and Y.M. Bontekoning. Opportunities for or in intermodal freight transport research: A review. European Journal of Operational Research, 153(2):400-416, 2004.

C. Macharis and A. Verbeke. Een multicriteria-analyse methode voor de evaluatie van intermodale terminals. Tijdschrift Vervoerswetenschap, 4, 1999.

A. Marín. Formulating and solving splittable capacitated multiple allocation hub location problems. Computers \& Operations Research, 32(12):3093-3109, 2005.

T.S. Meinert, A.D. Youngblood, G.D. Taylor, and H.A. Taha. Simulation of the railway component of intermodal transportation. Technical report, Arkansas University, Fayetteville, AK, 1998.

550 M.B. Pedersen. Optimization models and solution methods for intermodal transportation, 2005. Centre for Traffic and Transport - Technical University of Denmark. 
I. Racunica and L. Wynter. Optimal location of intermodal freight hubs. Transportation Research Part B: Methodological, 39(5):453-477, 2005.

B.J.C.M. Rutten. On medium distance intermodal rail transport. PhD thesis, Delft University of Technology, 1995.

A. Sirikijpanichkul and L. Ferreira. Multi-objective evaluation of intermodal freight terminal location decisions. In Proceedings of 27th Conference: Australian Institute of Transport Research, 2005.

A. Sirikijpanichkul, Van Dam, et al. Optimizing the location of intermodal freight hubs: an overview of the agent based modelling approach. Journal of Transportation Systems Engineering and Information Technology, 7(4):71-81, 2007.

UIRR. $\mathrm{CO}_{2}$ reduction through combined transport, 2009. International Union of combined Road-Rail transport companies.

UNECE. Illustrated glossary for transport statistics, 2009. United Nations Economic Commission for Europe.

H. Venables and A. Moscardini. Ant Colony Optimization and Swarm Intelligence, chapter An Adaptive Search Heuristic for the Capacitated Fixed Charge Location Problem, pages 348-355. Springer Berlin / Heidelberg, 2006.

H. Venables and A. Moscardini. Ant Colony Optimization and Swarm Intelligence, chapter Ant Based Heuristics for the Capacitated Fixed Charge Location Problem, pages 235-242. Springer Berlin / Heidelberg, 2008.

I.M. Whittley and G.D. Smith. The attribute based hill climber. Journal of Mathematical Modelling and Algorithms, 3(2):167-178, 2004.

B.W. Wiegmans, E. Masurel, and P. Nijkamp. Intermodal freight terminals : an analysis of the terminal market. Serie Research Memoranda 0055, VU University Amsterdam, Faculty of Economics, Business Administration and Econometrics, 1998. URL http: //ideas.repec.org/p/dgr/vuarem/1998-55.html. 